\title{
2.2. Alfabetización académica en entornos digitales
}

\section{Olaizola, Andrés [ver currículum del autor, docente de la Facultad de Diseño y Comunicación]}

\section{Abstract de Proyecto:}

Las tecnologías de la información y la comunicación cambiaron la manera en que leemos, escribimos y pensamos. En este escenario, surgen nuevos géneros, nuevas estructuras y nuevas maneras de componer textos. Los entornos digitales expanden la concepción de escritura: junto a las palabras se pueden utilizar imágenes, video, audio, animaciones, elementos interactivos, etc. Estas nuevas formas de leer y de escribir repercuten en todos los ámbitos sociales y culturales, incluida la esfera de la educación superior. Internet y los diversos dispositivos y medios digitales han transformado cómo investigamos, producimos, analizamos, diseñamos, enseñamos y aprendemos. A partir de este contexto, en el presente Proyecto de Exploración de la Agenda Profesional, nos proponemos indagar cómo la lectura y la escritura en entornos digitales pueden integrarse al proceso de alfabetización académica. Consideramos que para lograr una formación estratégica y actualizada de las y los estudiantes, la enseñanza de las prácticas discursivas y de pensamiento del ámbito académico debería incluir el diseño y el análisis de textos, espacios o documentos digitales para informar, persuadir, motivar a la acción, etc., las cuales son competencias centrales para sus carreras y futuros desempeños profesionales.

Palabras clave:

digital - enseñanza - hipertexto - tecnología.

Introducción

Durante los últimos veinte años, el proceso de enseñanza de la lectura y la escritura académica en el ámbito de la educación superior ha experimentado avances considerables, sobre todo debido a una toma de conciencia 
por parte de las instituciones ante las dificultades que experimentan gran parte de los estudiantes en lo que respecta a la comprensión y elaboración de productos discursivos científico-académicos.

Si bien muchas instituciones de educación media tienen instancias curriculares o extracurriculares relacionadas con la lectura y escritura en el ámbito académico, lo cierto es que no todos los alumnos ingresantes a la universidad poseen estos conocimientos previos. Antes de que se comenzaran a implementar en el nivel superior asignaturas sobre alfabetización académica, la institución les pedía a estos estudiantes que adquirieran en muy poco tiempo todo un bagaje de nuevos conocimientos teóricos, formales y metodológicos. Es más, les pedía que en unas cuantas clases ya formaran parte de una cultura discursiva completamente nueva. Por otro lado, aquellos alumnos que tenían una cierta formación en la producción y la comprensión de géneros discursivos académicos, al ingresar en el nivel superior, debían ser capaces de integrar los nuevos conocimientos con los antiguos, perfeccionándolos, logrando una mayor sistematización de los mismos. Este esquema profundizaba las diferencias de conocimiento de los estudiantes, en gran medida marginando a aquellos que carecían de las prácticas de lenguaje y de pensamiento correspondientes al ámbito académico.

Desde mediados de la década del noventa, esta situación ha venido cambiando. Distintas instituciones de educación superior fueron agregando en sus planes de estudio asignaturas, talleres o seminarios para alfabetizar académicamente a los alumnos ingresantes. En la Facultad de Diseño y Comunicación de la Universidad de Palermo, el proceso de alfabetización académica es llevado a cabo a partir de las materias Introducción a la Investigación y Comunicación Oral y Escrita.

Casi en forma paralela a este proceso, las nuevas tecnologías de la información y la comunicación se fueron incorporando en el ámbito educativo, ganando cada vez más espacio en currículos, en las estrategias de enseñanza e inclusive en el espacio físico del aula, ya que de sólo contar con clases periódicas en el aula de informática se ha añadido en el último tiempo el modelo 1 a 1 (una laptop o netbook por alumno1 ). A partir de la revolución digital, surgen nuevos géneros discursivos, estructuras textuales y formas de comunicar y construir el conocimiento.

Este nuevo contexto comunicacional añade un nuevo ámbito al concepto de alfabetización. A la alfabetización básica (correspondencia sonido-grafía, capacidad de oralizar un escrito) y a la alfabetización funcional y social (comprensión del texto, discriminación de datos relevantes e irrelevantes, etc.), se suma la alfabetización electrónica o digital, es decir, el conjunto de prácticas comunicativas escritas desarrolladas en este medio y los procesos de enseñanza y aprendizaje de las mismas (Cassany, 2002). La escritura y la lectura en entornos digitales poseen una serie de características específicas (hipertextualidad, multimodalidad, intertextualidad proactiva explícita, simultaneidad, interactividad, etc.) que requieren estrategias de producción y comprensión críticas, a menudo más complejas que las que se necesitan en entornos analógicos. Diversos estudios confirman que para lograr un manejo efectivo de las tecnologías digitales es necesario una gran cantidad de entrenamiento, mayor que la práctica requerida para el dominio de las tecnologías analógicas (Williams y Rowlands, 2007, p. 10).

En el presente Proyecto de Exploración de la Agenda Profesional, nos proponemos indagar cómo las nuevas formas de lectura y escritura en entornos digitales pueden integrarse a la alfabetización académica. A su vez, analizaremos si los géneros discursivos originados por las nuevas tecnologías de la información y la comunicación pueden utilizarse en el proceso de enseñanza y aprendizaje de la lectura y escritura académica. 
El proyecto consta de seis secciones. En primer lugar, en la sección del "Encuadre acadé- mico" se especificará para qué carrera o espacio curricular se desarrolla la exploración. La segunda sección, "Presentación del proyecto", detalla las características específicas del proyecto, señalando su fundamentación, su tipología, las necesidades que cubre y su descripción pormenorizada. En "Organización de la exploración" se expondrá la estructura para el desarrollo del proyecto, distinguiendo el rol del docente y el de los alumnos, el cronograma previsto y la metodología de evaluación. En la cuarta sección, "Encuadre teó- rico”, se detallan los vínculos que posee el proyecto con otras teorías o modelos del campo disciplinar, pedagógico, etc. Finalmente, se desarrollan las conclusiones y especifica la bibliografía utilizada en la elaboración del proyecto.

\section{Encuadre académico. Carrera o especialización profesional. Área}

El presente Proyecto de Exploración de la Agenda Profesional se desarrolla para todas las carreras de la Facultad de Diseño y Comunicación de la Universidad de Palermo. El proyecto se enmarca en las materias Introducción a la Investigación y Comunicación Oral y Escrita, las cuales conforman el Núcleo de Formación Académica. Estas asignaturas, dictadas en el primer año de todas las carreras de la facultad, brindan contenidos formativos generales, vinculados con el desarrollo de competencias y destrezas imprescindibles para los estudios universitarios. Se espera que los alumnos que cursen el Núcleo de Formación Académica puedan desarrollar habilidades metodológicas para la investigación, ejercitar la escritura y la lectura académica, elaborar documentos universitarios y perfeccionar la expresión oral.

Los lineamientos y las estrategias que se establecerán en el proyecto servirán para complementar los contenidos del Núcleos de Formación Académica, al incluir los parámetros, las prácticas y las diferentes formas de lectura y escritura electrónicas. Los esquemas de construcción y transmisión de conocimiento en entornos digitales requieren habilidades y competencias diferentes a las que entran en juego en la lectura y la escritura analógicas, ya que en los espacios electrónicos, el lector/escritor se enfrenta con textos hipertextuales y multimodales.

Es nuestro deseo que las reflexiones, las estrategias y las conclusiones que origine este proyecto no sólo se integren en las asignaturas del Núcleo de Formación Académica, sino que sean de utilidad a otras materias de distintas carreras, porque la comprensión crítica y la producción adecuada de textos en soporte electrónico es fundamental para la formación del estudiante y el desempeño laboral del futuro profesional de Diseño y Comunicación. El proyecto, por lo tanto, se ubicaría en el área disciplinar de la Pedagogía.

Presentación del proyecto. Fundamentación. Tipología

En un artículo ya clásico, Pierre Bourdieu y François Gros (1990), presidentes de una comisión creada por el Gobierno francés en 1988 para delinear los parámetros para una reforma de los planes de estudios, establecen algunos principios para la selección de contenidos. En aquella oportunidad, los autores ya habían subrayado la necesidad de transmitir "modos de pensamiento dotados de validez y aplicabilidad generales" y de enseñar un conjunto de técnicas y métodos relacionados con la formación académica, un contenido que pocas veces se transmitía de forma sistemática. Bourdieu y Gross afirmaban que bridar diversas técnicas de trabajo intelectual, estrategias de indagación e inculcar métodos racionales de trabajo a todos los alumnos sería "un modo de contribuir a la reducción de las desigualdades vinculadas a la herencia cultural". A partir de este antecedente, varios autores trabajaron sobre la alfabetización académica y sus implicancias en la formación de los alumnos 
universitarios (Adelstein, López Casanova, Inza, Korfield, Kruguel, Muslip, Pereira, Peralta y Resnik, 1998-1999; Alvarado y Yeannoteguy, 2009; Arnoux, Di Stefano y Pereira, 2000; Botta y Warley, 2007; Carlino, 2003, 2004, 2006, 2010; Cassany, 2008, 2009; Ciapuscio, 2000; Di Stefano y Pereira, 2004).

Los anteriores trabajos conforman una importante base teórica, sin embargo, los docentes muchas veces no encuentran las herramientas, las estrategias de enseñanza adecuadas para transmitir a los alumnos los lineamientos críticos y metodológicos de la comprensión y la producción de textos académicos. La estructuración de ciertos elementos formales de la comunicación académica puede ir en detrimento del elemento motivacional necesario para un aprendizaje significativo y con sentido. Los estudiantes se enfrentan con prácticas y géneros discursivos nuevos, con formas de comunicación y esquemas de pensamiento diferentes a los que están habituados. Por otro lado, muchos docentes suponen erróneamente que la escritura y la lectura son "habilidades separadas e independientes del aprendizaje de cada disciplina" (Carlino, 2010, p. 22).

A este panorama se le suma las nuevas formas de lectura y escritura originadas por las tecnologías de la información y la comunicación (Landow, 1995, 1997; Cassany, 2000, 2002, 2005, 2006; Prado Aragonés, 2001, Di Marzo, 2006; Manovich, 2006; Millán, 2008; Martínez Rodrigo y González Fernández, 2010, entre otros). Si bien gran parte de los alumnos son "nativos digitales" (Prensky, 2001a, 2001b), diversos estudios (Fallows, 2005; Martí Cartes, 2006, 2008; Williams y Rowlands, 2007, entre otros) evidencian que muchos miembros de la "Generación Google"2 presentan dificultades para buscar información relevante, identificar la credibilidad de las páginas Web y leer de manera crítica. Es necesario entonces guiarlos a través de un proceso de alfabetización digital, ya que la comprensión y producción de textos en soporte electrónico conlleva nuevas maneras de seleccionar, evaluar y procesar la información, explicar y argumentar, etc.

El Centro de Investigación de Escritura en Entornos Digitales (Writing in Digital Environments Research Center, 2005) de la Universidad Estatal de Michigan explica que las redes de computadoras crean un nuevo tipo de espacio de escritura, que cambia dramáticamente el proceso de composición, los productos textuales y la dinámica retórica básica entre lectores y escritores.

La Asociación Internacional de Lectura sostiene que, en el contexto actual, para estar plenamente alfabetizados, los estudiantes deben dominar las nuevas prácticas de lectura y escritura de las tecnologías de la información y la comunicación. Esto implica que los docentes deben integrar de manera efectiva dichas tecnologías en sus clases, y sobre todo, tienen que coadyuvar a los alumnos, para que se desarrollen como consumidores críticos y creadores informados, estableciendo parámetros para evaluar la relevancia, rigurosidad, confiabilidad y perspectiva de la información en línea (International Reading Association, 2009).

La alfabetización académica y la alfabetización digital a menudo se presentan como procesos separados, con muy pocos o ningún punto de contacto. Desde nuestra perspectiva, consideramos que para lograr un aprendizaje significativo y con sentido de las habilidades y estrategias fundamentales para la lectura y escritura académicas, las herramientas y las actividades que se utilizan para su enseñanza deben incluir los esquemas de comprensión y de producción de textos en entornos digitales. De esta manera, se abordarían las dos problemáticas al mismo tiempo: se alfabetiza académicamente aprovechando las posibilidades y las ventajas del entorno digital y, al hacerlo, también se transmiten las prácticas y competencias necesarias para leer y escribir adecuada y críticamente en dicho entorno. En lo que respecta a la tipología del proyecto, se puede clasificar 
como exploración y descripción de una innovación o tendencia en pedagogía y didáctica del Diseño y la Comunicación.

Necesidad que cubre

Al reflexionar sobre el tipo de profesionales que debe formar la educación superior, Juan Ignacio Pozo (2001) sostiene que en el contexto socioeconómico actual es "imprescindible la formación de profesionales con capacidad estratégica". La dinámica del mercado laboral, el irrefrenable cambio tecnológico y el esquema de pensamiento predominante, que privilegia la inmediatez en un marco de "modernidad líquida", hacen necesario que se modifique el perfil del profesional que se intenta formar, privilegiando el desarrollo del análisis crítico, el conocimiento estratégico y la creatividad. La escritura posee la potencialidad de desarrollar estas capacidades cognitivas, siempre y cuando, a partir de la planificación, la redacción y la revisión, se tenga en cuenta al destinatario y lo que se quiere lograr con el texto (Carlino, 2010, pp. 26-29). El proceso dialéctico entre el conocimiento previo del escritor y las exigencias retóricas para construir un texto eficaz, proceso que redunda en desarrollar y transformar el propio pensamiento del escritor, es uno de los contenidos fundamentales de la alfabetización académica.

Si al poder epistémico que tienen la escritura y la lectura se le suma el aprendizaje sistemá- tico de las habilidades y las competencias intelectuales que entran en juego en las prácticas comunicativas electrónicas, se proyectará la formación de un profesional capaz de generar y organizar ideas, formular objetivos, resolver problemas, actuar de manera estratégica, evaluar y revisar los resultados, tanto en entornos analógicos como digitales.

Uno de los objetivos del presente proyecto es explorar las dificultades de los estudiantes en lo que respecta a la alfabetización digital y, en consecuencia, proyectar actividades de producción y de comprensión para facilitar el aprendizaje significativo y con sentido de las prácticas de lenguaje y de pensamiento desarrolladas en los entonos digitales. A primera vista, este análisis podría parecer innecesario, ya que existe la creencia muy difundida de que la mayoría de los estudiantes, miembros de la Generación Google, navegan, escriben y leen como expertos en Internet. Sin embargo, varias investigaciones empíricas demostraron lo contrario. A continuación, citamos algunos de los estudios más recientes sobre el tema.

Entre los años 2000 y 2003, Beatriz Fainholc (2004) y su equipo entrevistaron a más de trescientas cincuenta personas para reconocer las características de los procesos de lectura/ navegación que realizan los usuarios en sitios de Internet. Si bien casi un 53 \% reconoció que no toda la información que aparece en la red es verdadera, el estudio concluyó que los usuarios no poseen "una evaluación realista de los recursos de Internet, en su dimensión de soporte valioso para la gestión autónoma de conocimiento como en su faz negativa, intrusa y disruptiva de información que ahoga y hace naufragar" (92).

Deborah Fallows (2005) entrevistó a dos mil doscientos usuarios habituales de motores de búsqueda de Internet. La mayoría de los entrevistados se sentían confiados con sus habilidades de búsqueda y estaban satisfechos con los resultados que encontraban. Además, el 68 \% consideró que los motores de búsqueda son justos e imparciales. Sin embargo, el estudio reveló que en realidad la gran mayoría de los entrevistados desconocía cómo funcionaban los motores de búsqueda. El $62 \%$ no sabía distinguir entre los enlaces patrocinados o no, y sólo el $18 \%$ afirmaba que siempre podía diferenciar entre estos dos tipos de enlaces. 
Fallows concluyó también que los usuarios más experimentados poseían una mirada más escéptica de los motores de búsqueda y los utilizaban de manera más crítica. Geoffrey Nunberg (2005) sostiene que muchos estudiantes tienen una confianza desmesurada en los resultados de sus búsquedas de material en Internet y a menudo ignoran que en las bibliotecas "analógicas" pueden acceder a otros recursos, como archivos de periódicos y de diarios, colecciones de mapas antiguos, etc. Nunberg comparte su experiencia como docente universitario en una asignatura sobre calidad de la información y relata que incluso sus alumnos, que están altamente entrenados en motores de búsqueda, tienen dificultades con actividades que involucran evaluar información en línea sobre áreas que desconocen. Peter Williams e lan Rowlands (2007, pp. 9-11) explican que los miembros de la Generación Google carecen de estrategias para buscar información pertinente. Los autores citan estudios que muestran que, para realizar la búsqueda, los nativos digitales, en lugar de usar términos clave, utilizan preguntas y frases completas, y en lugar de emplear el vocabulario especializado de las asignaturas, se expresan en lenguaje cotidiano e informal; además, tampoco se evidencia que planifiquen la búsqueda con antelación. A su vez, los estudiantes analizados no saben aprovechar las distintas herramientas que les ofrecen los motores de búsqueda de Internet para acelerar su indagación. Williams y Rowlands detallan que los estudiantes dedican muy poco tiempo a evaluar críticamente la información en línea; es más, prácticamente no siguen ningún criterio para seleccionar material de Internet, con lo cual tienen problemas para la identificación de fuentes confiables, pertinentes y legitimadas. Irónicamente, afirman los autores, la falta de pericia en la búsqueda de información de los estudiantes podría explicarse por la errónea percepción de que es sencillo buscar materiales en Internet, sobre todo porque no han recibido en la institución educativa una enseñanza sistemática al respecto.

Francina Martí Cartes (2008) llevó adelante un estudio de caso con alumnos del nivel medio donde debían evaluar páginas Web que hablaban sobre drogas. La investigación demostró que para la valoración de los sitios utilizaron criterios poco elaborados, sin una reflexión sistemática. Los estudiantes no cuestionaron la autoridad de las páginas Web y centraron su atención en aspectos más formales, como el diseño.

Daniel Cassany y Gilmar Ayala (2008, pp. 63-64) sostienen que los nativos digitales "son buenos en las cuestiones más superficiales y mecánicas (qué teclas hay que apretar, cómo se instala un programa, etc.), pero carecen de conocimientos más especializados para navegar y procesar información de manera más estratégica". El equipo de investigación de los autores realizó varios estudios que muestran que los alumnos catalanes del nivel medio "no están acostumbrados a leer de manera crítica textos auténticos periodísticos" y que tienen "dificultades para identificar la credibilidad y la intención de webs sobre temas corrientes", pero subrayan que ninguno de los estudiantes había recibido instrucción formal al respecto.

Esperamos que el proyecto permita delinear estrategias, actividades y herramientas didácticas para que los alumnos, a partir de las posibilidades comunicativas y cognitivas de los textos en soporte electrónico, desarrollen una lectura crítica y una escritura con conciencia retórica, competencias necesarias para formar parte de la cultura discursiva de la educación superior.

\section{Descripción pormenorizada}

Hasta el momento, en el presente proyecto hemos utilizado determinados conceptos teó- ricos y críticos que fueron sucintamente definidos. A continuación, y para terminar de constituir nuestras categorías de análisis, 
ampliamos y profundizamos las definiciones de alfabetización académica y alfabetización digital y detallamos las características distintivas de los textos en soporte electrónico.

La alfabetización académica se concibe como "el conjunto de nociones y estrategias necesarias para participar en la cultura discursiva de las disciplinas así como en las actividades de producción y análisis de textos requeridas para aprender en la universidad" (Carlino, 2010, pp. 13-14). El concepto engloba, por un lado, las prácticas de lenguaje y los esquemas de pensamiento del ámbito académico; y por el otro, el proceso a través del cual se logra ingresar como miembro a la comunidad científica y/o profesional, "precisamente en virtud de haberse apropiado de sus formas de razonamiento instituidas a través de ciertas convenciones del discurso".

Partiendo desde el concepto de literacy (término inglés que es la traducción de "alfabetización", pero que también incluye a toda la cultura organizada alrededor del escrito3 ), Bill Green (2002) propone una visión más integral de la competencia en las prácticas en escritura y lectura, a partir de tres dimensiones o aspectos: operacional, cultural y crítico. El aspecto operacional incluye conocer cómo funciona el lenguaje, uso de la gramática, géneros discursivos, etc. El aspecto cultural está integrado por conocimientos de cultura literaria y escrita, análisis del contexto de producción de los textos, etc. Finalmente, el aspecto crítico conlleva una visión crítica de los textos, en términos de relaciones de poder, indagando el propósito de los textos, a quienes se les da la voz y a quienes no, etc.

La cultura escrita, de modo cada vez más rápido, está migrando hacia entornos digitales o electrónicos. En este contexto, explica Cassany (2006, p. 173), "surgen nuevas prácticas comunicativas, con nuevos géneros (correo electrónico, conversación o chat, página o sitio), estructuras (hipertexto, intertextualidad), registros (tecleado, coloquial) y formas lingüísticas". Todas estas formas de producir, transmitir y adquirir conocimiento imponen capacidades comunicativas específicas, diferentes a las que se delinean en los procesos de alfabetización básica y alfabetización funcional y social. La alfabetización digital, por lo tanto, puede definirse como "el conjunto de habilidades, conocimientos y actitudes (técnicos, lingüísticos, cognitivos, sociales), que se requieren para comunicarse con la tecnología electrónica" (Cassany, 2006, p. 177). Específicamente, entre las habilidades necesarias para construir y comprender textos en soporte digital pueden incluirse habilidades de computación (manejar la máquina, los programas, el teclado, el mouse, etc.), habilidades verbales (manejar el lenguaje escrito u oral de cada uno de los géneros discursivos), habilidades visuales y auditivas (utilizar archivos multimedia) y habilidades de navegación o de "literacidad informativa" (buscar, encontrar, evaluar y usar información).

Los textos en entornos digitales poseen una serie de rasgos distintivos en el plano pragmá- tico, discursivo, gramatical y de procesamiento. En el presente proyecto, nos enfocaremos en las características discursivas y cuáles son sus implicancias en la construcción del conocimiento y en la perspectiva retórica de la escritura académica.

En primer lugar, es menester distinguir los géneros discursivos4 a través de los cuales se desarrolla la comunicación en Internet. Los géneros electrónicos o digitales pueden clasificarse en sincrónicos (chat, juegos en línea de múltiples jugadores, mundos virtuales, etc.), en los cuales escritor y lector interactúan en tiempo real, y asincrónicos (correo electrónico, foros, blog, página Web, wikis, etc.), donde los interlocutores leen y escriben en distintos momentos (Cassany, 2006, p. 196). Desde ya, la clasificación de los géneros no debe tomarse como algo rígido, sino que simplemente es un intento de sistematización que sirve, en gran medida, para propósitos 
didácticos. Existen diversos géneros electrónicos que se ubican entre el polo sincrónico y el polo asincrónico. Las redes sociales, por ejemplo, incluyen formas de interacción en tiempo real y otras que descansan en la comunicación en diferido. En lo que respecta a las características discursivas de los textos en entornos digitales, podemos destacar la hipertextualidad, la intertextualidad explícita y proactiva y la multimodalidad. Para completar el análisis, por un lado, desarrollaremos el aspecto de los enlaces, fundamentales para el discurso hiper e intertextual. Por el otro lado, observaremos de qué manera los rasgos distintivos de los textos digitales modifican los esquemas cognitivos y los lineamientos del proceso argumentativo.

\section{Hipertextualidad}

El hipertexto, estructura básica del discurso en entornos digitales, es una tecnología informática compuesta de bloques de textos individuales, o lexías, y enlaces electrónicos que los vinculan entre sí. Los fragmentos de textos hipertextuales pueden incluir información verbal, gráfica, audiovisual, sonora, etc. Por lo tanto, tal como propone Adelaide Bianchini (1999: 3), podríamos resumir que el hipertexto es una tecnología que maneja y organiza información en una red de nodos (conformados por textos escritos, audiovisuales, sonoros, visuales, además de códigos ejecutables y otras formas de datos) conectados por enlaces u órdenes de programación.

George P. Landow (1995, p. 16) explica que los nexos electrónicos unen lexías externas e internas a una obra, por lo tanto, configuran "un texto que el lector experimenta como no lineal5 o, mejor dicho, como multilineal o multisecuencial". Ted H. Nelson (1981, citado en Landow, 1995, p. 15), quien acuñó el término "hipertexto" en 1965, sostiene que "con hipertexto me refiero a una escritura no secuencial, a un texto que se bifurca, que permite que el lector elija y lea mejor en una pantalla interactiva". La estructura hipertextual quiebra la linealidad del texto, rompe la secuencia unidireccional de oraciones e ideas, permitiendo que los lectores puedan elegir entre varios itinerarios de lectura posibles y así "moverse a través de la información y hojear intuitivamente los contenidos por asociación, siguiendo sus intereses en búsqueda de un término o concepto" (Bianchini, 1999, p. $3)$.

El soporte digital, que permite fracturar la linealidad propia de los soportes analógicos, "confiere al texto una arquitectura poliédrica, lo abre y lo expande, lo fragmenta y lo convierte, gracias a las redes, en ubicuo y participativo" (Vásquez Rocca, 2004, p. 3). En la estructura hipertextual, el lector puede desplazarse constantemente a través de una red de textos, por lo tanto, constantemente desplaza el eje organizador, el centro de su investigación, de su lectura. El hipertexto proporciona un sistema que puede centrarse, descentrarse y recentrarse hasta el infinito, y cuyo centro de atención provisional depende de los intereses propios de lector, que así se convierte en un verdadero lector activo (Landow, 1995, p. 24). Laura Di Marzo (2006), por su parte, explica que el hipertexto no sólo ha cambiado la forma de leer y de escribir, sino que implica cambios en las estructuras del conocimiento. El discurso hipertextual posee una miríada de conexiones posibles con nodos de información y de conocimiento. Este nuevo esquema de representación y pensamiento conlleva cambios en la educación. A la creación de lectores críticos se le debe sumar la tarea de formar "hiperlectores", que comprenden que hay casi infinitas maneras de organizar la información y que pueden discernir su nivel de pertinencia. Más adelante se desarrollará con detalle estos puntos. 
Así como los enlaces electrónicos unen unidades, bloques o lexías de un mismo texto electrónico, configurando de este modo la estructura básica hipertextual, los nexos pueden vincular el texto con otras lexías o textos electrónicos externos. Las relaciones que se establecen entre distintos escritos digitales configuran un nuevo tipo de intertextualidad, diferente a la que mantienen los textos en soporte analógico.

Las conexiones entre textos digitales desarrollan una intertextualidad proactiva explícita (Cassany, 2000, pp. 46 ), porque los enlaces se refieren a sitios Web actuales o del futuro (en tanto las páginas se actualizan), y porque, a través del sistema de vínculos coloreados, subrayados o iluminados, el autor/lector navega entre documentos sin darse cuenta de que cambia de texto y de autor, con lo cual, las nociones de unidad textual, contextualización espacio-temporal y autoría tienden a desvanecerse. De esta manera, explica Cassany (2002, p. 6), en los textos digitales, "emerge a la superficie la consabida polifonía e intertextualidad bajtiniana, que permanecía escondida en el documento analógico: redactores y lectores somos más conscientes de la naturaleza social del discurso y de la simple función de coautoría que ejercemos en la construcción del entramado discursivo de una comunidad". A partir de la estructura hipertextual y de su intertextualidad explícita, el texto digital se configura como un objeto comunicativo abierto, versátil, interconectado y significativo (Cassany, 2006, p. 194).

\section{Enlaces}

Sin los enlaces electrónicos, la estructura hipertextual no podría sostenerse y las relaciones de intertextualidad proactiva explícita no se llevarían a cabo. Es menester aclarar que la importancia de los enlaces no sólo se reduce a la función formal, arquitectónica, que desempe- ña en la conformación de los textos en entornos digitales; antes bien, varios autores (Burbules, 1997; Burbules y Callister, 2001; Cassany, 2006; Martí Cartes, 2006; Salmerón González, 2006, entre otros) señalan el papel central que tienen en la construcción del contenido.

El usuario/lector medio, o "navegador", considera que los vínculos son neutros, pasivos, sin ideología, cuyo único propósito es conectar las distintas partes del sitio Web o distintas páginas entre sí. En contraposición, un escritor y lector crítico, un "hiperlector", como el que aspiramos a formar en el nivel superior, está atento a los vínculos y no los subestima, porque los enlaces son mecanismos activos, creadores de significado, elementos fundamentales de la estructura retórica del texto digital.

Si consideramos que en la lectura el significado se construye a partir del conocimiento previo, es decir, con los datos que se acaban de leer y con la información que se recupera de la memoria, entonces los enlaces electrónicos que conectan los distintos textos influyen en la comprensión. El lector leerá de determinada manera (y no de otra) de acuerdo a los vínculos a través de los cuales llegó al texto digital. Cassany (2006, p. 195) explica que "cada enlace crea un itinerario de lectura particular e irrepetible, porque contextualiza cada fragmento con los textos vinculados, sean los que leemos previamente o a continuación". Para desarrollar una lectura crítica de los enlaces no sólo es fundamental saber que diferentes vínculos pueden configurar diferentes aproximaciones e interpretaciones de un texto, sino que también es necesario destacar que los enlaces fueron creados con una intención determinada, por lo tanto, no son todos iguales ni suponen la misma relación semántica. Nicholas Burbules y Thomas Callister (2001, p. 139) subrayan que si bien todos los enlaces de un texto hipertextual funcionan de la misma manera, implican la misma acción (cliquear sobre una palabra o ícono resaltado) y el resultado es casi siempre el mismo (surge una pantalla nueva), no todos son de la misma 
especie, por lo tanto, "elegir y seguir una determinada línea de asociaciones entre puntos textuales distintos conlleva un proceso de inferencia o un análisis del carácter de la asociación que implica el enlace seleccionado".

Martí Cartes (2006, p. 27) analiza los enlaces desde una perspectiva ideológica y retórica y sostiene que el uso y la ubicación de los vínculos es uno de los medios principales por los que se manifiestan en un texto hipertextual los valores tácitos del autor. Los vínculos expresan sentidos, razones, revelan prejuicios y motivaciones, impulsan o sugieren inferencias y tratan de persuadir, de manipular al lector para que comprenda el texto de una manera específica. No basta simplemente con seguir el rumbo que proponen los autores, sino que, para desarrollar la hiperlectura, hay que interpretar el significado de los enlaces, evaluar su grado de adecuación y sugerir nuevos vínculos, formas distintas de asociar el material (Burbules y Callister, 2001, p. 149).

\section{Multimodalidad}

Un aspecto central de los textos en soporte digital es que permiten integran otros sistemas de representación del conocimiento en un único formato. En un texto analógico, el discurso se organiza en torno a la escritura como modo de representación del significado, de hecho, si hay imágenes, éstas están subordinadas a la lógica y al principio ordenador de la secuencia temporal de la escritura (Kress, 2004). Los textos digitales no sólo se componen de letras y oraciones, sino que también hay video, fotos, gráficos, audio, animaciones, etc., por lo tanto, el texto adquiere la condición de multimodal.

Desde la perspectiva de la semiótica social, Gunther Kress (1998, 1999, 2004, 2005) analiza la multimodalidad con el objetivo de describir los potenciales y las limitaciones del significado en los diferentes modos de representación. Para los textos multimodales, el autor propone una mirada integral, estableciendo que el lenguaje verbal y el lenguaje visual pueden complementarse, interactuar entre sí, para multiplicar su capacidad expresiva cuando se refuerzan mutuamente (Kress, 1998, citado en Cassany, 2006, p. 180). En un texto constituido multimodalmente, cada modo, interaccionando con los demás sistemas de representación, contribuyen parcialmente al significado total del discurso.

La integración de los diferentes modos semióticos se da en el texto multimodal a través de dos códigos simultáneos: el modo de composición espacial y el modo de composición temporal. El primer modo opera en textos en donde los elementos están ordenados de manera de espacial, por ejemplo, pinturas, gráficos, fotografías, páginas de revistas, etc. El modo de composición temporal opera en textos (discurso oral, discurso escrito, música, danza) que se desarrollan en el tiempo, a partir de una secuencia temporal (Kress \& van Leeuwen, 2006, p. 177). Los textos en soporte digital trabajan con los dos modos de composición, por lo cual, como ya mencionamos, no sólo son necesarias habilidades verbales para comprender la prosa lineal, sino también se necesitan habilidades visuales y auditivas para leer los distintos modos de representación presentes.

Según Kress (2004), en los entornos digitales, en la pantalla, la escritura, basada en la linealidad, en la secuencia temporal, queda subordinada a la lógica de lo espacial, por lo tanto, la comprensión y el análisis de un texto digital, de una página Web, debe también basarse en tres principios de composición visuales: information value (valor de información), entendido como la propiedad que determina que el posicionamiento de los elementos en varias zonas de la imagen (arriba, abajo, derecha e izquierda) los dota con los valores informativos específicos de dichas zonas; salience (prominencia o resalte), que especifica que los elementos pueden atraer la atención del lector/usuario en distintos grados, a partir de su posicionamiento en primer plano o en el fondo, 
tamaño relativo, contraste en el valor tonal, diferencias de nitidez, etc.; y framing (encuadre), que explica que la presencia o ausencia de dispositivos de encuadre (que pueden ser elementos que crean líneas divisorias o directamente las líneas que componen los marcos) conecta o desconecta elementos de la imagen, estableciendo que están o no vinculados de alguna manera (Kress \& van Leeuwen, 2006, p. 177).

Los textos en soporte digital, a partir de la posibilidad de integrar diversos modos de representación del conocimiento que interactúan entre sí para construir significados, y sobre la base de la arquitectura hipertextual, se configuran como complejos sistemas de representación de la información. Para la adecuada comprensión de este tipo de textos es necesario la formación de hiperlectores (Burbules y Callister, 2001; Martí Cartes, 2006) que puedan distinguir lo que es útil, creíble o interesante, que tengan la capacidad crítica de leer la información de manera selectiva, evaluarla y cuestionarla, que pongan en duda los enlaces, que sean competentes para utilizar y decodificar sistemas y textos audiovisuales, sonoros y visuales.

Por otro lado, también deberían formarse escritores de textos digitales que tengan en cuenta la corrección gramatical, la cohesión, la coherencia y la adecuación textual; que adopten una perspectiva retórica (conciencia del destinatario y del propósito de la escritura); y que además puedan utilizar de manera estratégica los enlaces, las posibilidades semánticas de los diferentes modos de representación y los procesos y las técnicas de la retórica visual y digital (DeVoss, Cushman y Grabill, 2005; DeVoss y Porter, 2006; DigRhet.org, 2006; Handa, 2001; Heba, 1997; Hocks, 2003; Lanham, 1992; Losh, 2009; National Writing Project, DeVoss, Eidman-Aadahl y Hicks, 2010; Porter, 2002, 2009; Reeves et al, 2004; Stroupe, 2000; Sullivan, 2001; Welch, 1990; Writing in Digital Environments Research Center, 2005; Wysocki, 1998, 2001, 2004; Zappen, 2005). En un entorno multimodal, el diseño es un tema central, ya que el autor, al tener diferentes vías de comunicar y de componer su mensaje, debe decidir qué modo es el mejor, el más apto para el contenido que se desea transmitir, cuál de los modos de representación es el más adecuado para los destinatarios a los que se dirige y cuál se corresponde con sus intereses y propósitos (Kress, 2004).

\section{Proceso de construcción del conocimiento}

Los rasgos distintivos de los textos en entornos digitales no sólo originan nuevas formas de leer y de escribir, sino que también influyen en los procesos cognitivos implicados en la comprensión y producción textual. Una nueva práctica comunicativa, que genera un discurso diferente, propicia el desarrollo de "formas alternativas de organización de la comunidad y nuevos estilos de informar, comprender y pensar" (Cassany, 2006, p. 214).

Las nuevas tecnologías de la información y la comunicación transforman el pensamiento individual de tal manera que se evidencia una clara diferenciación entre los procesos cognitivos que desarrollan los nativos y los inmigrantes digitales. Basándose en investigaciones en neurobiología, Mark Prensky (2001b) sostiene que los nativos digitales tendrían diferentes estructuras cerebrales a partir de los estímulos a los que han estado y están permanentemente expuestos; es decir, los niños y los jóvenes que nacieron y crecieron con la revolución digital en marcha, que desde edad temprana manejan, interactúan e integran a su vida cotidiana las TIC poseerían cerebros fisiológicamente diferentes a los cerebros de los inmigrantes digitales, quienes tuvieron una infancia "analógica". Los estímulos digitales pueden provocar transformaciones en el cerebro, ya que éste tiene la capacidad de "reorganizarse" constantemente durante toda la vida (neuroplasticidad), con lo cual la forma de pensar también cambia. 
Prensky (2001b), además, se basa en la psicología social y explica que el entorno y la cultura en la que las personas se crían influyen e incluso determinan muchos de sus procesos de pensamiento. Entonces, los niños que crecieron rodeados de teclados, monitores y teléfonos celulares, que ya navegan en Internet incluso antes de aprender a leer, pensarían en forma diferente, desarrollarían mentes "más hipertextuales" y sus razonamientos se apoyarían sobre todo en estructuras cognitivas paralelas antes que secuenciales. Por esta razón, Prensky sostiene que los procesos de pensamiento lineal, que dominan los sistemas educativos actuales, pueden convertirse un obstáculo en el proceso de aprendizaje de aquellas personas que han desarrollado su esquema de pensamiento a partir de los videojuegos y de la navegación en Internet. Estrella Martínez Rodrigo y Ana María González Fernández (2010, p. 7) confirman las conclusiones de Prensky y explican que "los nativos digitales son multitarea, con estructuras neuronales específicas que los convierten en pensadores sofisticados, debido a que sus mentes se han desarrollado de manera paralela al hipertexto, es decir, de forma no lineal y basada en una cultura audiovisual". Las palabras de las autoras subrayan dos elementos, dos ejes sobre los que podemos organizar el análisis de la argumentación en textos electrónicos: la no linealidad y la multimodalidad. Esta primera aproximación a la retórica digital, desde luego, no pretende abarcar la miríada de aspectos que entran en juego en este nuevo concepto, como por ejemplo, el funcionamiento y la reconfiguración de las estrategias retóricas tradicionales en entornos digitales, la creación de identidades individuales y de comunidades, etc.

\section{Argumentación}

Las palabras de Prensky y de Martínez Rodrigo y González Fernández resaltan una vez más que las TIC no sólo propiciaron cambios en las técnicas y en los dispositivos físicos de escritura y de lectura. Los entornos digitales configuran formas totalmente diferentes de acceder, utilizar, construir y comunicar la información y el conocimiento.

Según Roger Chartier (2008, p. 34), a diferencia de los cambios producidos en la escritura y en la lectura a partir de la invención de la imprenta, que no alteró la estructura básica del libro, la revolución digital "modifica todo a la vez, los soportes de la escritura, la técnica de su reproducción y diseminación, y las maneras de leer". El quiebre del vínculo entre texto y objeto acentúa la discontinuidad y la fragmentación de la lectura, y la descontextualización del discurso.

El carácter hipertextual del texto electrónico modifica también la dinámica de la argumentación, ya que en lugar de basarse en un desarrollo lineal, deductivo, utilizando técnicas clásicas argumentativas, el discurso en entorno digital es abierto, relacional y multimodal, y le confiere al receptor un papel activo en la construcción del conocimiento. Chartier (2008, p. 37) explica que el lector de un texto argumentativo digital "puede comprobar la validez de cualquier demostración consultando por sí mismo los textos (pero también las imágenes, las palabras grabadas o composiciones musicales) que son el objeto del análisis si, por supuesto, están accesibles de forma digitalizada". De esta manera, las técnicas clásicas de la prueba (notas a pie de página o al final, citas directas e indirectas, referencias, distintas formas de contaminación de voces, etc.), que suponían que el lector confiara en el análisis del autor, experimentan una profunda modificación. La revolución de la textualidad digital, por lo tanto, "constituye también una mutación epistemológica que transforma las modalidades de construcción y acreditación de los discursos del saber (Chartier, 2008, p. 37). 
Uno de los objetivos del proceso de alfabetización académica es que los alumnos puedan producir y analizar textos argumentativos. El manejo competente de este tipo de textos es central en las prácticas discursivas y de pensamiento del ámbito de la educación superior, en general, y de cada una de las disciplinas, en particular. En el presente proyecto, consideramos que para lograr una adecuada formación académica y profesional, actualizada y estratégica, es necesario incluir las prácticas comunicativas escritas originadas a partir de las TIC, para que los alumnos sean capaces de comprender y componer textos del género discursivo académico, tanto en entornos analógicos como digitales.

La retórica clásica ordena las partes del discurso argumentativo (dispositio) a través de una estructura que implica principio (exordio), medio (narratio, confirmatio) y final (epí- logo). A su vez, la confirmatio o exposición de los argumentos también debe poseer una estructura, ya que "el orden expositivo de los argumentos es en sí mismo un argumento" (Alvarado y Yeannoteguy, 2009, p. 73). Tradicionalmente, la argumentación encuentra su soporte en un texto oral o escrito que se organiza por la lógica y el principio ordenador de la secuencia en el tiempo (Kress, 2004); por lo tanto, el fin principal del texto unilineal sería representar el conocimiento en forma de secuencia lineal progresiva, de menos a más (Vásquez Rocca, 2004, p. 4). El discurso argumentativo necesita del establecimiento de un centro, de una línea. David Kolb (1997, p. 369), que analiza las implicancias del concepto de la no linealidad en la filosofía, sostiene que todo texto filosófico obra en virtud de la línea argumentativa de su estructura general: un argumento une premisas y conclusión.

El texto argumentativo en soporte analógico, basado en la linealidad, se contrapone a la estructura hipertextual, que puede tener múltiples comienzos y finales, en donde el lector, al elegir uno u otro enlace, tiene la opción de seguir desarrollos argumentativos paralelos, opuestos, complementarios, alternativos o completamente diferentes. El hipertexto cuestiona la lógica subordinativa que ha imperado en el pensamiento occidental y reivindica los modelos asociativos y coordinativos que se encuentran en concordancia con el paradigma holístico y transdisciplinario de la postmodernidad (Vásquez Rocca, 2004, p. 5).

Hemos visto que los textos en soporte digital, a partir de su propia naturaleza constitutiva, nos invitan a reflexionar acerca del proceso de construcción de la argumentación, explicitando que es posible desarrollar varias dinámicas argumentativas, que se pueden seguir otros caminos retóricos, diferentes al del modelo tradicional. Varios autores, al analizar la no linealidad del hipertexto, ya rastrean esta propiedad en textos tan antiguos como el I Ching (Aarseth, 1997, pp. 85-87). Kolb (1997, p. 373), por ejemplo, menciona que Aristóteles, en Segundos analíticos, dice que una cadena de argumentos puede estar anclada en premisas que son evidentes por sí mismas y por tanto no necesitan argumentos (esquema lineal) o puede ser circular (esquema no lineal). Las glosas y las diversas notas marginales de los códices medievales, con sus comentarios, ampliaciones, aclaraciones, yuxtaposiciones, objeciones y réplicas, referencias a otros textos, etc., también podrían considerarse como formas que desvían y cuestionan la linealidad de los discursos argumentativos.

La no linealidad, entonces, se presenta como una categoría que no es completamente extraña al proceso argumentativo tradicional, "analógico"; de hecho, Kolb (1997: 374) considera que la filosofía política de Hegel, que consiste en tratamientos lineales de una secuencia de categorías detalladas y períodos históricos, presentaría una estructura en donde "la transición de una categoría a otra resulta ser un aspecto de una transición mayor, que a su vez resulta ser un momento en un movimiento mayor aún, y así sucesivamente hasta el mayor movimiento del sistema, que reviste la forma de un círculo y no de una línea, con comienzo y final". 
El discurso argumentativo encuentra en los entornos digitales el medio indicado para explorar las potencialidades, las ventajas, y también los límites, de un esquema retórico no lineal. Esto no significa que el tratamiento lineal ya no es válido en un texto digital, sin embargo, en cierto sentido, quedará subsumido a la lógica hipertextual, al modo de composición espacial. Landow (1995, p. 78) sostiene que la retórica lineal, que encadena argumentos ordenados secuencialmente, seguirá apareciendo dentro de los bloques de textos del hipertexto, "pero no podrá ser utilizada para estructurar argumentos en un medio que anima a recorrer caminos diferentes en vez de seguir uno lineal". Si bien consideramos un tanto extrema la posición de Landow de desestimar el uso de la retórica lineal en la argumentación hipertextual, sus palabras proporcionan un buen punto de partida para reflexionar acerca de los modos de representación y las estructuras específicas de los entornos digitales y cómo necesariamente influyen y transforman las estrategias argumentativas.

Kolb (1997) reconoce las posibilidades que abre la hipertextualidad para la construcción del discurso argumentativo (en su caso, enfocado en la filosofía), pero a la vez niega que los enlaces puedan ser las formas, las figuras indicadas para llevar a cabo un proceso retó- rico. Para el autor, los enlaces simplemente conectan unidades, realizan meras conexiones, las cuales son muy diferentes a las relaciones dialécticas o a la constitución mutua. Los vínculos, según Kolb, “carecen de la fecundidad contingente de la yuxtaposición inmediata y el carácter de autorreferencia de los giros textuales ingeniosos, [...] pueden cambiar las relaciones de una lexía y su papel dentro de un todo [...], pero no la hacen reflejar o exceder su propia unidad" (379). Por todo lo anterior, Kolb concluye que el discurso argumentativo hipertextual necesita de algún tipo de forma y figura además de la adición, debe descubrir nuevas maneras de representar interacciones complejas que no sean las unidades lineales jerárquicas estándar, pero tampoco las vistosas yuxtaposiciones ni la simple conexión entre tema y comentario.

El pedido de Kolb para que se desarrollen nuevas formas y figuras para componer textos argumentativos digitales surgiría del desconocimiento de que efectivamente existen nuevos tropos y nuevas estrategias que se originan a partir de los entornos electrónicos. El análisis de Kolb trata de adaptar, de acomodar las características de los textos digitales a las categorías de análisis de la retórica lineal: se intenta explicar y subsumir el modo de composición espacial a la lógica de la secuencia temporal. En realidad, creemos que un correcto análisis debería ser no sólo al revés (adaptar y reconfigurar las formas de la retórica analógica a lo digital), sino que el proceso de comprensión y producción de textos digitales argumentativos debería analizarse utilizando específicamente los lineamientos teóricos y prácticos de su retórica específica, la retórica digital.

Antes de centrarnos en este último aspecto, es menester referirnos a ciertos elementos relacionados con las figuras y las formas que pedía Kolb para los textos hipertextuales, y para ello es interesante destacar el aporte de Espen Aarseth (1997, pp. 101-102), quien reflexiona acerca de la retórica de la no linealidad. Aarseth explica que los textos no lineales desafían los conceptos básicos de la teoría de la literatura, ya que, "la no linealidad como superconjunto del hipertexto no es claramente un género literario, ni un tipo de expresión o discurso poético". En lo que respecta a la retórica, el autor sostiene que la no linealidad no es un tropo, porque opera a nivel de palabras y no de significado, pero agrega que sí podría clasificarse como un tipo de figura según la clásica taxonomía de tropos y de figuras retóricas de Pierre Fontanier, Les figures du discours (1821-1830), donde se definen "las figuras que no son tropos" (les figures non-tropes) y se las clasifica en clases (figuras de construcción, figuras de elocución, figuras de estilo y figuras de pensamiento) y subclases (inversión, aposición, elipsis, repetición, etc.). Aarseth, entonces, reflota este antiguo inventario de figuras y se basa en su clasificación 
para considerar a la no linealidad como una "figura no tropo", la cual tendría sus respectivas subclases: bifurcación, enlace o salto, permutación, cómputo y poligénesis.

\section{Retórica digital}

Más allá de sus diferentes perspectivas de análisis, los trabajos de Kolb y Aarseth ponen en evidencia que, a partir de sus rasgos distintivos de los textos en entorno digital, es necesario adoptar una nueva postura para el proceso de enseñanza de los géneros discursivos académicos. Las nuevas formas de leer y de escribir que surgen a partir de las tecnologías de la información y la comunicación deberían formar parte de cualquier curso que imparta producción y análisis de textos propios de la cultura escrita de la educación superior. La alfabetización académica ya no puede sólo abarcar prácticas discursivas y de pensamiento derivadas de un entorno analógico, de un esquema de composición lineal y donde predomina la información verbal.

Hoy en día, la enseñanza de los géneros discursivos académicos debería también incluir los modos de leer y de escribir y los esquemas de pensamiento que posibilitan el soporte electrónico. El análisis y la producción de textos académicos digitales tienen que integrar la práctica y la competencia en hipertextualidad y multimodalidad. La argumentación en medios digitales interactivos se basaría, entonces, en la no linealidad (híper e intertextualidad, enlaces), en los diferentes modos de representación del conocimiento (audio, video, imágenes, animaciones, etc.), en la retórica visual y también en la retórica lineal clásica. Los nuevos medios y sus prácticas de lenguaje y de pensamiento son formas híbridas, por lo tanto, utilizan al mismo tiempo una gramática verbal y una gramática visual. Si se acepta la constitución híbrida de los géneros electrónicos, se entiende que, en el discurso argumentativo digital, los textos verbales y los textos (audio) visuales, la cultura "de la escritura impresa" y la cultura "visual", establecen relaciones dialógicas antes que de oposición binaria (Hocks, 2003, p. 631).

Tal como explicamos, en los textos en entornos digitales lo visual y lo verbal se entrelazan tanto que resulta muy difícil separarlos, de hecho, las palabras y las imágenes están imbricadas de tal manera que prácticamente son indistinguibles en la pantalla (Wysocki, 2001). Richard Lanham (1993, citado en Hocks, 2003, p. 630), profesor de Inglés en la Universidad de California, parte de esta característica de los textos electrónicos interactivos para enfatizar la naturaleza retórica de la escritura digital y sostener que la retórica digital recobra la paideia retórica al hacer explícitos aspectos de la retórica oral y visual que fueron olvidados a lo largo de los últimos dos siglos de cultura y convenciones de la palabra impresa. James Porter (2009), profesor en el departamento de Escritura, Retórica y Cultura Estadounidense en la Universidad Estatal de Michigan, coincide con Lanham y sostiene que los entornos digitales, las comunicaciones basadas en Internet, permiten resucitar el canon de la representación (actio) y el canon de la memoria de la retórica clásica, que fueron desterrados de la enseñanza de la composición y de la argumentación durante el siglo XIX y principios del siglo XX a partir de una perspectiva ideológica que impuso una retórica occidental, masculina, aria y abstracta.

La enseñanza de las estrategias y técnicas necesarias para la producción y el análisis de textos digitales requieren que los docentes articulen ciertos lineamientos y ejes temáticos de alfabetización visual, en general, y de retórica visual, en particular. La retórica visual, entendida como las estrategias visuales utilizadas para significar y persuadir, adquiere una importancia central en la lectura y escritura en soporte electrónico. Las nuevas tecnologías de la información construyen significados a través de una gramática híbrida, que es al 
mismo tiempo visual, verbal e interactiva, por lo tanto, la retórica digital integra, adopta el uso de la retórica visual así como otras modalidades (Hocks, 2003).

Los docentes tienen que guiar a los alumnos para que tomen conciencia de los aspectos retóricos de los entornos digitales. Mary E. Hocks (2003, p. 631), profesora de Composición y Retórica digital en la Universidad Estatal de Georgia, sostiene que es necesario remarcar la naturaleza visual de estos actos retóricos, y a la inversa, la naturaleza retórica de esos actos visuales, y entenderlos como formas híbridas de lectura y escritura desarrolladas en el medio digital de Internet.

¿Pero qué es específicamente la retórica digital? DigiRhet.org (2006), un colectivo de estudiantes, profesores e investigadores de la Universidad Estatal de Michigan, interesados en la temática de las prácticas de escritura electrónica, delinearon los siguientes puntos para tratar de definir qué es la retórica digital: 1. Una nueva forma de comunicación compuesta, creada y distribuida a través de las nuevas tecnologías; 2. La exploración de la dinámica de la argumentación a través del uso de elementos digitales, como hipervínculos interactivos y archivos de imagen y de audio; 3. El uso de la tecnología digital para aumentar la comprensión de un mensaje por parte del lector/usuario/audiencia; 4. El arte de informar, persuadir y motivar a la acción a una audiencia a través de los medios digitales; 5 . Las formas en que cambian las prácticas de lectura y escritura y la dinámica entre escritores y lectores cuando los textos y otros elementos se mueven en la red; 6 . La conciencia crítica sobre cómo la elección de incorporar o excluir diferentes elementos digitales afecta el mensaje; 7. Y el análisis de los aspectos distintivos de un bloque de información digital, tales como uso del espacio, esquema de color y elementos interactivos, para entender cómo mejorar un argumento o mensaje (242). Para Hocks (2003, p. 632), la retórica digital se centra en las múltiples modalidades disponibles para construir significado utilizando las nuevas tecnologías de la información y la comunicación. De esta manera, la retórica digital describiría un sistema dinámico de diálogo y negociaciones entre escritores, audiencia y contextos institucionales.

Por su parte, Elizabeth Losh (2009, pp. 47-48), directora del Programa de cultura, artes y tecnología de la Universidad de California, propone cuatro diferentes definiciones de retórica digital: 1. Las convenciones retóricas de los nuevos géneros digitales usadas en el discurso cotidiano y en el discurso de las ocasiones especiales; 2. La retórica pública, usualmente en la forma de mensajes políticos de instituciones gubernamentales, que es representada o registrada a través de tecnologías digitales y diseminada vía redes de distribución electrónicas; 3. La emergente disciplina académica que se ocupa de la interpretación retórica de los medios digitales en tanto objetos de estudio; 4. Las teorías matemáticas de la comunicación del campo de las ciencias de la información, muchas de las cuales tratan de cuantificar el grado de incertidumbre en un intercambio lingüístico dado o las posibles vías a través de las cuales viajan los mensajes. A su vez, Jim Ridolfo, uno de los integrantes del colectivo DigiRhet.org (2006, p. 243), define a la retórica digital como un objeto o series de objetos comunicativos que son creados, mantenidos o diseminados a través de o dentro de ambientes binarios. Estos objetos o actos comunicativos pueden incluir texto, elementos visuales y sonidos. La retórica digital, agrega Ridolfo, posee la propiedad única de ser "inmaterial" y no enfrenta directamente los límites físicos de la actio (la representación del discurso frente a la audiencia), que limita a la retórica analógica.

Las distintas variables que entran en juego en la retórica digital, y que se reflejaría en las amplias definiciones de DigiRhet.org, Hocks, Losh y Ridolfo, llevan a que James P. Zappen (2005, p. 323), profesor de Retórica en el Instituto Politécnico Rensselaer, considere que la retórica digital es una amalgama de componentes más o menos discretos antes que una teoría completa e integrada. Sin embargo, Zappen aclara que esos componentes 
discretos proporcionan un esbozo para dicha teoría, que tiene el potencial para contribuir, en general, al corpus de la teoría y de la crítica retórica, y en particular, a la retórica de la ciencia y la tecnología. A grandes rasgos, para el autor, los estudios teóricos sobre retórica digital ayudan a explicar cómo funcionan y cómo son reconfiguradas las tradicionales estrategias retóricas en los espacios digitales (319).

La enseñanza de retórica digital requiere profundos cambios en cómo pensamos la escritura y la pedagogía. Analizar y producir textos en entornos digitales ofrece, por un lado, una oportunidad para que los alumnos desarrollen sus habilidades retóricas y se formen como autores más reflexivos y críticos, y por el otro, establece una nueva pedagogía de la escritura como diseño (Hocks, 2003, p. 632). Por lo tanto, la retórica digital delinea los usos estratégicos de los varios modos de representación del conocimiento, de las dos estructuras organizativas (linealidad y no linealidad) y de la retórica visual para la construcción o el análisis de discursos argumentativos en entornos digitales.

Tal como propone el segundo punto de la definición de retórica digital de DigiRhet.org, una de las estrategias que el escritor/lector/diseñador/usuario puede desarrollar en un entorno digital para construir, recibir o reaccionar ante un determinado significado es la utilización de los enlaces interactivos. Cuando tratamos el tema de los links, destacamos la posición de Burbules y Callister (2001, pp. 138-149), quienes sostenían que los hipervínculos, en el mismo momento en que conectan los nodos textuales, construyen significados distintos, ya que fueron creados de antemano por un autor que tenía un determinado propósito.

La anterior consideración partía del hecho de que a menudo se subestima la importancia de los vínculos al tratarlos como meros atajos neutrales subordinados a las fuentes de información a las que permiten acceder. Justamente, la opinión de Kolb (1997) sobre los enlaces es tributaria de esta postura, contra la cual Burbules y Callister proponen un enfoque más crítico y reflexivo. Una de las maneras de desarrollar un mayor discernimiento, de ejercitar la hiperlectura, es entender a los distintos tipos enlaces como diferentes tropos retóricos que sugieren maneras distintas de relacionar los elementos que unen. Burbules y Callister enumeran las siguientes figuras retóricas que codifican diferentes clases de enlaces: - Metáfora: el enlace asocia, compara dos puntos sin relación aparente e invita al usuario a hallar similitudes entre ellos y a cambiar el concepto sobre el primero, "trasladando" de uno al otro características hasta entonces inconexas. El vínculo que funciona como metá- fora le pide al lector que vea un nodo enlazado como otro distinto.

- Metonimia: se establece una asociación entre dos puntos que no se basa en la similitud, sino en la continuidad, en las relaciones prácticas. Burbules y Callister explican que un enlace, casi por definición, "tiene la capacidad de volverse metonímico por la repetición" (143).

- Sinécdoque: en el entorno de Internet, este tropo (que designa un todo con el nombre de una de sus partes o viceversa) identifica o sugiere relaciones de inclusión en las que intervienen categorías. Los enlaces que representan categorías se establecen a menudo como una forma para controlar el acceso a la información, ya que limitan y modelan lo que las personas piensan sobre un tema.

- Hipérbole: la dinámica de Internet se establecería sobre esta figura retórica, en tanto que opera aumentando o disminuyendo excesivamente aquello de lo que se habla o se silencia, aquello que forma parte o no de su estructura hipertextual ("en la Web está todo", "lo que no está en la Web no existe", etc.). 
- Antístasis: este tropo supone la repetición de una misma palabra con acepciones distintas o contradictoras, es decir, destaca los modos en que un término o concepto cambia de sentido en contextos diversos. Según Burbules y Callister, el efecto de este tipo de enlaces "consiste en ubicar todos los fenómenos dentro del mismo espacio semántico, pasando por alto factores temporales y espaciales así como el contexto discursivo" (145), de esta manera, se yuxtaponen bloques de información aparentemente inconexos y se los reduce al mismo nivel de sentido.

- Recurso de identidad: cuando se asocia por medio de la identidad, que específicamente no es un tropo, el mismo punto se emplea para resaltar elementos de coincidencia. Las vinculaciones por identidad niegan la diferencia y subrayan la equivalencia, por lo tanto, estas asociaciones "tienden a establecer líneas de conexión entre las páginas originadas por personas, instituciones, culturas o países distintos, como si esos puntos de referencia crearan una red unificadora que abarcara la multiplicidad superficial de contenido y entornos que forman parte de la Web" (147).

- Relaciones de secuencia y de causa-efecto: los enlaces que sugieren asociaciones secuenciales o causales no se limitan a relacionar ideas o nodos de información, sino que también aseveran o implican creencias acerca del mundo externo, de la "realidad". Los enlaces no explicitan que realizan dichas asociaciones, sólo las manifiestan.

- Catacresis: esta figura consiste en dar a una palabra sentido traslaticio6, para designar algo que carece de nombre especial, es decir, determinados usos artificiosos o inadecuados de palabras conocidas en un contexto nuevo. Burbules y Callister sostienen que la catacresis es inherente al funcionamiento básico del enlace, en tanto que "es posible enlazar dos cosas cualesquiera, y a partir de allí comienza un proceso de desplazamiento semántico" (148).

La utilización de los enlaces como tropos es una de las formas para argumentar en entornos digitales. Otra de las maneras para persuadir, para fundamentar determinada hipótesis, es a través de los videos. Losh (2008), por ejemplo, analiza cómo agencias gubernamentales estadounidenses y británicas emplean los videos de sus canales oficiales en YouTube para legitimar políticas internas impopulares y reafirmar y extender las concepciones de soberanía, seguridad y subjetividad construidas por el discurso estatal.

Para la enseñanza de las estrategias de producción y de análisis de textos argumentativos digitales es necesario sistematizar los múltiples elementos que pueden participar en la dinámica de la argumentación electrónica. A partir de esta consideración, sería posible utilizar el esquema de Hocks (2003, p. 632), quien propone tres conceptos que ayudarían a describir cómo opera la retórica digital: - Postura de la audiencia: las formas en las que la audiencia es invitada a participar en los documentos on line y las formas en las que el autor crea un ethos que requiere, motiva o incluso desanima diferentes tipos de interactividad por parte de esa audiencia.

- Transparencia: las formas en las que los documentos on line se relacionan con convenciones estéticas establecidas, como las de la imprenta, el diseño gráfico, los filmes y las páginas Web. Cuanto más el documento digital toma de esas convenciones familiares, más transparente será para la audiencia.

- Hibridez: las formas en las que los documentos on line combinan y construyen diseños visuales y verbales. La hibridez de los entornos digitales también alienta a que los autores y la audiencia reconozcan y construyan 
identidades multifacéticas.

Si aceptamos esta propuesta, la construcción del discurso argumentativo en espacios digitales e interactivos se basaría en la utilización de tres variables simultáneas que se interrelacionan entre sí para lograr persuadir a la audiencia. Hocks sostiene que las tres categorías proveerían un punto de partida para comenzar a analizar los aspectos retóricos y visuales de los textos en entornos digitales, los contextos apropiados para diseñar estos documentos como argumentos visuales, y el potencial impacto de estos diseños en la audiencia, particularmente a través del uso de la interfaz y de la interactividad (643).

Organización de la investigación

En el siguiente apartado, describiremos la estructura prevista para el desarrollo del proyecto. Realizaremos una primera aproximación al papel de los docentes y de los alumnos, detallaremos algunas estrategias de enseñanza y actividades didácticas y propondremos un cronograma de trabajo y una metodología de evaluación.

\section{Docentes}

Tal como expusimos en el Encuadre académico, el presente proyecto englobaría a los docentes de las materias Introducción a la Investigación y Comunicación Oral y Escrita. Desde nuestra perspectiva, y basándonos en los trabajos citados sobre alfabetización y retórica digital, las prácticas de lectura y escritura electrónicas y las nuevas formas de construir significado a través de diversas modalidades y de esquemas de composición no lineales deberían integrarse al proceso de la alfabetización académica, ya que son competencias fundamentales para la formación integral del alumno.

El estudiante que aspiramos desarrollar es un hiperlector crítico de fuentes de Internet, es un escritor/diseñador capacitado para construir textos adecuados, coherentes y cohesivos en entornos analógicos y digitales, con conciencia retórica de la situación de comunicación, y que, en el caso de los textos electrónicos, puede discernir qué modo de representación y qué estructura formal utilizar para informar mejor, relatar, persuadir o motivar a la acción. Todas estas prácticas de lenguaje y de pensamiento se vinculan y están imbricadas en el resto de la carrera y en la futura práctica profesional.

Para comenzar a trabajar estos contenidos verbales, procedimentales y actitudinales, los docentes podrían desarrollar primero los rasgos distintivos de la lectura y la escritura en entornos digitales. Sobre esta base conceptual, se explicaría cómo se complejiza el proceso de construcción del discurso argumentativo, ya que no sólo se basa en la retórica lineal, sino que ahora requiere un abordaje multimodal, hipertextual e interdisciplinario. En este punto, sería posible ir introduciendo cuestiones referidas a la retórica visual y a la gramática híbrida de los textos en entornos digitales. Finalmente, se trataría la temática de la retórica digital, subrayando que es una disciplina en constante evolución y que las producciones de los alumnos son aportes para dicho proceso.

\section{Estudiantes}

En la anterior sección, expusimos una primera aproximación que podrían realizar los docentes a la producción y al análisis de textos académicos en entorno digital. La breve descripción de los pasos a seguir no incluía la parte práctica, la cual se desarrollará en el presente apartado. Es menester aclarar que si bien en el proyecto se 
presentan separadas, teoría y práctica no se encuentran en compartimentos diferentes, sino que están imbricadas una en la otra. Bourdieu y Gros (1990) argumentan que se debe hacer lo posible para mitigar la oposición entre teoría y técnica, entre lo formal y lo concreto, entre lo puro y lo aplicado. Paula Carlino (2010), por su parte, explica que para que los estudiantes se adueñen de cualquier contenido tienen que reconstruirlo una y otra vez. La lectura y la escritura son herramientas fundamentales en la tarea de asimilación y transformación del conocimiento, por lo tanto, "los alumnos necesitan leer y escribir para participar activamente y aprender" (25).

A continuación, presentaremos algunas actividades grupales e individuales, con sus correspondientes consignas y objetivos. Cabe destacar que en la alfabetización académica se tiende a utilizar predominantemente actividades de lectura y escritura individuales, ya que suele imperar la idea de que la composición es un proceso en solitario, en donde el autor está solo frente al papel o la pantalla. Es menester realizar una breve aclaración al respecto. Si partimos de la base de que el lenguaje es social y que se adquiere y desarrolla a partir de la interacción con los otros, las actividades de lectura y de escritura deben fomentar la interrelación entre los aprendices. Cassany (2001) considera que escribir cooperativamente es central en el proceso de enseñanza de la composición, ya que "los compañeros pueden ayudar a un autor aprendiz a buscar ideas, a organizarlas, a revisar los borradores". Los aprendices de escritores pueden intercambiar opiniones sobre el texto, el proceso de composición, la planificación, etc. "Dialogar, conversar, escuchar son formas de captar ideas, de desarrollarlas, de interpretarlas, de prepararlas para la escritura" (Cassany, 2001).

Actividades grupales

A partir de las consideraciones anteriores, las siguientes actividades tratan de aprovechar el potencial didáctico del trabajo en grupo.

La primera actividad se centra en la búsqueda de distintos tipos de fuentes por Internet. En grupos de tres miembros, los alumnos buscarán un determinado documento y registrarán todo el proceso. Al anotar todos los pasos, al preguntarse por qué hicieron tal o cual acción, los alumnos toman distancia de este proceso tan cotidiano y pueden analizarlo críticamente. Se trata de motivar una primera reflexión acerca de cómo es el proceso de búsqueda que realizan. Esta autoevaluación podría ser el punto de partida para comenzar a trabajar con diversas guías de selección y evaluación de materiales en Internet (Bardi, Perazzo, Ruíz, Sosisky, 2007; Cassany, 2005, 2006; De Volder, Russo, Kolesas, 2010; Scagnoli, 2001).

La segunda actividad grupal se enfoca en las características distintivas de la lectura en soporte digital a partir de comparar los paratextos de tres sitios Web y el de un artículo de Daniel Cassany aparecido en la revista Lectura y vida.

Actividad No 1 Objetivos: buscar distintos tipos de fuentes en Internet, analizar el proceso de búsqueda de materiales en la Web, utilizar de forma competente los catálogos en línea de distintas bibliotecas.

Consigna: Susan Sontag (1933-2004) fue una novelista, ensayista y crítica literaria estadounidense. Específicamente en el género argumentativo, Sontag escribió ensayos sobre temáticas como el género, la enfermedad, el dolor y la fotografía. Para trabajar con el proceso de búsqueda de materiales en Internet se les propone lo siguiente: 
1. Formar grupos de tres miembros. Cada grupo debe tener por lo menos una computadora.

2. Los integrantes del grupo se dividirán dos tareas: búsqueda y registro. Específicamente, uno de los miembros se deberá encargar de la búsqueda en Internet, el segundo lo asistirá y el tercer miembro anotará todos los pasos que realizan los otros dos integrantes del grupo durante la búsqueda.

3. Una vez que se conformaron los grupos y que se han divido las tareas deberán realizar lo siguiente: a) Averiguar cuál es el título del ensayo de Susan Sontag sobre la fotografía.

b) Encontrar una fuente terciaria o secundaria que hable sobre el ensayo de Sontag.

c) Encontrar una biblioteca donde haya un ejemplar del ensayo.

d) Si es posible, encontrar un sitio Web donde haya una versión digitalizada sobre el ensayo.

4. El integrante que realice el registro de la búsqueda deberá describir los pasos y las acciones del proceso. Para hacerlo, seguirá la siguiente guía de preguntas: a) ¿Qué palabra o palabras pusieron primero en Google? ¿Limitaron la búsqueda? Si es así, ¿cómo limitaron la búsqueda? ¿Utilizaron alguna herramienta de Google (Google Noticias, Google Académico, Google Libros, etc.)? b) De las páginas que encontró Google, ¿a cuál fueron primero? ¿Por qué? c) ¿Usaron Wikipedia? ¿Para qué? ¿Utilizaron algún dato? d) ¿Cuál es el origen de la fuente terciaria o secundaria? ¿Diario, revista, revista digital, página Web, revista especializada? e) ¿En la página de qué biblioteca buscaron el texto? ¿Cómo utilizaron el catálogo en línea? ¿Pueden ir a la biblioteca? f) ¿Encontraron una versión digitalizada? Si la encontraron, ¿en qué página? Actividad № 2 Objetivos: identificar los elementos paratextuales de textos en soporte analógico y en soporte digital, comparar los paratextos de los textos, describir las características distintivas de la lectura en soporte analógico y en soporte digital. Consigna: En este módulo hemos visto los distintos elementos que conforman el paratexto de un texto. Tomando en cuenta la definición que realiza Genette ("un aparato montado en función de la recepción") y las características descriptas por Maite Alvarado en su libro Paratexto, se le propone lo siguiente: 1. Formen grupos de tres miembros. Cada grupo debe tener por lo menos una computadora.

2. Identifiquen y marquen los elementos paratextuales presentes en el artículo de Daniel Cassany "De lo analógico a lo digital. El futuro de la enseñanza de la composición". Cassany, Daniel. (2000). De lo analógico a lo digital. El futuro de la enseñanza de la composición. Lectura y vida, 21/4, pp. 6-15.

3. Las siguientes páginas Web albergan artículos en soporte digital: Cada miembro del grupo debe elegir una de las páginas y visitarla. Una vez en la página elegida, cada miembro tiene que buscar un artículo de su interés e identificar los elementos paratextuales (para el relevamiento puede usar anotaciones en un documento del procesador de textos).

4. Comparar los elementos paratextuales que cada miembro del grupo identificó en el artículo en soporte digital que trabajó.

5. Maite Alvarado explica que el paratexto se constituye de elementos verbales y elementos icónicos. Comparen los elementos verbales (tapa, títulos, subtítulos, notas, bibliografía, etc.) y los elementos icónicos (gráficos, imágenes, fotos, ilustraciones, etc.) de los artículos de Cassany y de los tres artículos en soporte digital elegidos. 
6. Luego de haber leído textos en soporte analógico y en soporte digital, completar el siguiente cuadro, identificando las ventajas y las desventajas de la lectura en cada uno de los soportes:

\section{Actividades individuales}

El análisis de los elementos paratextuales permite construir una hipótesis de lectura sobre un texto. Esta estrategia de anticipación brinda información al lector acerca del tipo de género discursivo del texto, del tema que trata, de la audiencia a la que se dirige, etc. La primera actividad individual se centra en la etapa que sigue al análisis del paratexto: la lectura y su correcta comprensión. A fin de aprovechar más la actividad, el texto con el que se trabaja es parte de la bibliografía crítica sobre alfabetización digital. Tal como expusimos más arriba, teoría y práctica se presentan interrelacionadas, estableciendo una relación dialéctica.

La segunda activad se basa en las características de la Web 2.0 para fomentar el desarrollo de la escritura con conciencia retórica. Con anterioridad a la presentación de la consigna, es necesario que el docente cree un blog o un grupo o página de Facebook de la materia. Más allá de la presente actividad, este espacio puede ser creado al principio de la cursada para aprovecharlo como vía de comunicación y fuente de bibliografía y de documentación institucional. Volviendo a la consigna, los alumnos escribirán un texto argumentativo sobre un tema determinado, teniendo en cuenta lo que quieren lograr con el texto y la perspectiva del destinatario. Luego, los alumnos subirán el texto al blog o al grupo para que los compañeros lo lean y publiquen sus opiniones en el mismo espacio. Finalmente, el autor leerá los distintos comentarios y analizará si efectivamente el texto cumplió su propósito y si anticipó correctamente las expectativas de los distintos lectores.

La producción cooperativa de contenidos, estructuras y programas por parte de los usuarios y la interrelación entre los internautas es la base de la Web 2.0, concepto desarrollado en el año 2004 por el especialista en TIC y defensor del software libre Tim O’Reilly (2005). La dinámica de la Web 2.0 ofrecería la posibilidad de contar con un contexto real de publicación para los trabajos de escritura de los alumnos. El ensayo no quedará circunscripto a las paredes del aula, subrayando aún más su condición de constructo pedagógico, artificial, alejado de la realidad del alumno. El texto que deben construir saldrá a luz, aparecerá en un lugar donde puede ser leído por los compañeros, pero también cualquier persona que tenga acceso a la red.

Esta circunstancia llevaría a que los alumnos consideren seriamente la situación retórica de la composición. Las y los aprendices deberán analizar y valorar las condiciones y las características de los distintos elementos de la situación de comunicación: el perfil de la audiencia, el tema del que se habla, los códigos (lingüístico, sociocultural, ideológico, retórico), los propósitos del texto, etc. Este análisis sobre la propia escritura implica una reflexión crítica sobre el saber del aprendiz. Escribir con conciencia retórica desarrolla el conocimiento, lo transforma, ya que el autor debe establecer una relación dialéctica entre el problema retórico (referente a la comunicación efectiva con el lector) y el problema semántico (relacionado al contenido). Carlino (2010, p. 29) explica que "poner en relación los problemas de contenido con los problemas retóricos, intentando ajustar lo que sabe el que escribe a lo que precisaría el lector, es lo que permite transformar el conocimiento de partida". El escritor consciente de la situación retórica tiene presente el propósito del texto y las necesidades informativas de sus lectores, por lo tanto, adecuará el tema a la audiencia, cuestionará lo que sabe para exponerlo de manera más eficaz, reformulará el texto para mejorar la cohesión, la coherencia y la lógica argumentativa. Porter (2002, pp. 384-385) subraya que lo revolucionario de la escritura digital no es tanto la computadora aislada, la máquina per se, sino que la verdadera revolución consiste en la red de computadoras interconectadas y los contextos 
sociales y retóricos que crea y la forma en que su uso impacta en las prácticas de publicación. La conectividad e interactividad propiciadas por la TIC permiten que los escritores, por un lado, accedan a textos digitales, muchos de los cuales fomentan su participación activa, y por el otro, que distribuyan sus propias producciones a las más variadas audiencias.

Por su parte, National Writing Project (2010, p. 7), una red de docentes dedicada a mejorar la enseñanza de la composición en instituciones educativas primarias, secundarias y superiores, sostiene que la transformación más grande de la escritura digital son las formas interconectadas en la que es posible compartir, distribuir y archivar composiciones digitales usando tecnologías de Internet. En la actualidad, la interconectividad permite que los escritores puedan extraer contenidos de una miríada de fuentes, usar una variedad de modos, construir diferentes tipos de composición enmarcados en distintos géneros, y distribuir su trabajo casi instantáneamente y de manera global.

A partir de sus experiencias como alumnos y docentes de escritura digital, el colectivo DigiRhet.org (2006, pp. 243-247) especifica que para lograr un aprendizaje significativo y con sentido de estas nuevas prácticas letradas, los estudiantes necesitan construir una comunidad, desarrollar un análisis crítico y aplicar en situaciones reales los principios y estrategias de la retórica digital. Para los estudiantes, la comunicación en espacios digitales sólo adquiere sentido cuando observan la relevancia que tiene la retórica digital en sus vidas cotidianas y cuando comprenden cómo afectará en su futura vida profesional, por lo tanto, los docentes deberían diseñar actividades en donde los alumnos apliquen sus conocimientos sobre retórica digital en contextos comunicativos reales.

Actividad N $N^{0} 1$ Objetivos: construir una hipótesis de lectura a partir del paratexto, identificar y decodificar las marcas gráficas del sistema de citación, comprender el concepto teórico de la hipertextualidad, comparar las características del escrito analógico y del escrito digital, escribir un texto argumentativo breve.

Consigna: 1. A partir de los elementos paratextuales presentes en el artículo de Daniel Cassany "De lo analógico a lo digital. El futuro de la enseñanza de la composición”, construí una hipótesis de lectura sobre el texto.

2. A lo largo del artículo, Cassany utiliza muchos términos ligados a las nuevas tecnologías de la comunicación y de la información. Si no conocés alguna de las palabras, anotálas y buscá su significado en el siguiente diccionario en línea sobre neologismos vinculados a la informática: http://www.ati.es/gt/lenguainformatica/externos/sampedr3.html\#glosario

3. Leé el siguiente párrafo.

"Con la grafía el habla se cosifica, despersonaliza, descontextualiza, objetiviza, entre otras facultades (Cassany, 1999, p. 42), lo cual posibilita el desarrollo de géneros comunicativos nuevos".

¿Se vincula este párrafo con algún otro texto? En el caso de que se vincule, ¿cómo te das cuenta?, ¿hay algún tipo de marca especial?, ¿con qué texto se relaciona? Las preguntas, ¿tienen alguna otra función?

4. Al final de la página 3, Cassany escribe algunas preguntas. ¿A quién le realiza las preguntas? ¿Al lector o a él mismo? ¿Las preguntas se responden a lo largo del artículo? ¿Las preguntas pueden considerarse una guía del texto? 
5. El cuadro de la página 4 sintetiza las principales diferencias entre la comunicación en el entorno analógico y en el entorno digital. Leélo atentamente y contestá: ¿Hay algún término que desconozcas? ¿Cuál o cuáles? Hacé una lista con las palabras cuyo significado no conozcas y buscálas en el Diccionario de términos clave del Centro Virtual Cervantes: http://cvc.cervantes.es/ensenanza/biblioteca_ele/diccio_ele/default.htm

6. La siguiente es la definición del término "intertextualidad" del Diccionario de términos clave del Centro Virtual Cervantes: "Intertextualidad: La intertextualidad es la relación que un texto (oral o escrito) mantiene con otros textos (orales o escritos), ya sean contemporáneos o históricos; el conjunto de textos con los que se vincula explícita o implícitamente un texto constituye un tipo especial de contexto, que influye tanto en la producción como en la comprensión del discurso". Proporcioná tres ejemplos en donde se observe la relación de intertextualidad.

7. En la página 6, Cassany da una primera definición del término hipertexto: "En cambio, el entorno digital utiliza el hipertexto como estructura básica: el escrito lineal y unidireccional se rompe en diversidad de fragmentos autónomos que se conectan entre sí con enlaces (links) o llamadas que permiten saltar ágilmente de uno a otro, en cualquier dirección -como una araña que se desplaza a través de una telaraña o de una red-“.

Reformulá esta definición en dos enunciados: El hipertexto es... El escrito digital rompe con la linealidad porque...

8. ¿Qué quiere decir Cassany cuando explica que "el soporte digital rompe definitivamente la linealidad del discurso y organiza el contenido textual de manera hiper e intertextual"?

9. Completá el siguiente cuadro comparativo:

10.Cassany afirma que es necesario añadir un nuevo ámbito al concepto de alfabetización: el digital. ¿En qué consistiría un curso de "alfabetización digital”? ¿Qué habilidades se enseñarían?

11. Tomando como base los puntos que Cassany destaca en las páginas 10 y 11, elaborá un texto breve (no más de treinta líneas) donde expliques cómo impactan en el aula universitaria las nuevas formas de leer y escribir en soporte digital. Actividad № 2 Objetivos: escribir un texto del género discursivo académico, desarrollar la escritura con conciencia retórica, analizar el texto propio a partir de los comentarios de los compañeros.

\section{Consigna:}

1. Leer críticamente los siguientes artículos: Cleiman, Ana Laura, (2010). ¿Querés ser mi amigo? En versión siglo XXI. Miradas al Sur, 24 de octubre. Dehaes, Viviana, y Botta, Mayra. (2008). Redes sociales y comunidades del conocimiento. Debates: Educación y TIC. Educ.ar, 30 de mayo. Disponible en: http://portal.educ.ar/debates/educacionytic/nuevos-alfabetismos/redes-sociales-y-comunidades-d.php Sagol, Celia. (2009). Los límites de las redes sociales. Debates: Educación y TIC. Educ.ar, 28 de enero. Disponible en: http://portal.educ.ar/debates/educacionytic/nuevos-alfabetismos/los-limites-de-las-redes-socia.php

2. A partir de los artículos sobre Facebook, escribir un texto argumentativo sobre la temática de las redes sociales y su impacto en la educación. El texto deberá poseer una introducción, un cuerpo central y una 
conclusión. Se debe postular explícita o implícitamente la hipótesis personal, la cual debe tener argumentos que la justifiquen.

3. Durante la planificación, la producción y la revisión del texto argumentativo tener en cuenta el propósito del ensayo y la perspectiva de los futuros lectores.

4. Subir el texto definitivo al blog/grupo de la materia.

5. Luego de que todos los compañeros hayan comentado el texto, leer las opiniones y contestar: a) ¿Pudo cumplirse el propósito del texto? b) ¿Cómo fue la recepción del texto por parte de los lectores? c) ¿Fue posible anticipar correctamente las expectativas de la audiencia? ¿Sí? ¿No? ¿Por qué?

\section{Cronograma}

En la sección "Docentes" propusimos una primera aproximación al tratamiento en el aula del tema de la escritura y la lectura académica en entornos digitales. A su vez, en el apartado "Estudiantes" ensayamos algunas actividades para que los alumnos puedan poner en práctica los contenidos adquiridos. A partir de estos lineamientos, desarrollaremos un planteamiento más detallado, y si se quiere un poco más sistemático, para trabajar con los textos digitales argumentativos en el proceso de alfabetización académica. Se estableció un esquema tentativo de administración dividido en cinco clases, las cuales se describen a continuación: Primera clase Contenido: La lectura y la escritura en entornos digitales. Características pragmáticas, discursivas y gramaticales de los textos electrónicos. Hipertextualidad, intertextualidad proactiva explícita y multimodalidad.

Actividades: Actividad grupal № 2 (en clase). Actividad individual № 1 (trabajo práctico para el hogar).

Segunda clase Contenido: Lectura crítica de fuentes de Internet. Guías de selección y evaluación de materiales en la red.

Actividades: Actividad grupal № 1 (en clase). Entrega parcial de la actividad individual № 1.

Tercera clase.

Contenido: La escritura académica en entornos digitales. Cambios en el proceso de argumentación. Elementos de la retórica digital (hipertextualidad, multimodalidad, retórica visual, retórica lineal).

Actividades: Actividad individual $N^{\circ} 2$ (trabajo práctico para el hogar). Entrega definitiva de la actividad individual № 1.

Cuarta clase Contenido: Análisis y construcción de textos argumentativos digitales.

Actividades: Entrega parcial de la actividad individual № 2 .

Quinta clase Contenido: Análisis y construcción de textos argumentativos digitales. 
La evaluación no es un mero apéndice de los procesos de enseñanza y de aprendizaje, sino que está intrínsecamente relacionado con aquellos. La evaluación implica "juzgar la enseñanza y juzgar el aprendizaje; atribuirles un valor a los actos y las prácticas de los docentes y atribuirles un valor a los actos que dan cuenta de los procesos de aprendizaje de los estudiantes" (Litwin, 1998, p. 13). La evaluación genera información y juicios críticos sobre la enseñanza y el aprendizaje, por lo tanto, construye conocimiento "a lo largo de diferentes momentos del proceso educativo y no como etapa final" (Litwin, 1998, p. 17). El aprendizaje significativo requiere tiempos, no es una situación que se resuelve en un momento puntual y específico. Edith Litwin (1998, p. 14) sostiene que muy probablemente el verdadero aprendizaje tiene lugar cuando el alumno o la alumna se encuentran fuera de la clase en donde se planteó la situación de enseñanza. A raíz de estas consideraciones, las actividades proyectadas poseen una entrega parcial y una entrega final. El docente evalúa el trabajo intermedio y realiza las correcciones, comentarios y recomendaciones necesarias para ayudar al alumno a reescribir el texto. La calificación originada a partir de la entrega definitiva no sólo debería tener en cuenta los criterios de evaluación, sino que también sería necesario valorar el proceso de mejora, de reformulación que realizó el estudiante desde el primer trabajo. A su vez, esta dinámica de entrega parcial-retroalimentaciónentrega definitiva también responde al hecho que, tal como mencionamos anteriormente, la adquisición de las competencias específicas para la producción y el análisis de textos académicos digitales podría considerarse un proceso más complejo y que requiere más práctica que la lectura y escritura académica en entornos analógicos.

De Miguel Díaz (2004, p. 9) explica que la evaluación es esencialmente un problema de valores, porque es un proceso con el que se atribuye un valor a un objeto a partir de determinados criterios. Ya que lo que se evalúa es el aprendizaje, los objetivos del mismo pueden tomarse como criterios de evaluación. Es necesario entonces explicitar tanto los objetivos como los criterios, puesto que servirán para emitir un juicio de valor de la tarea desempe- ñada. Los criterios de evaluación para las actividades desarrolladas serían los siguientes:

a) Lectura analítica de los documentos y fuentes de Internet. Reconocimiento de las secuencias textuales presentes.

b) Identificación y exposición de forma clara y sistemática de las hipótesis, los argumentos y las perspectivas de análisis. c) Texto adecuado, cohesivo y coherente. La redacción respeta las reglas gramaticales y ortográficas.

d) Uso crítico de las diferentes técnicas expositivas-explicativas y las técnicas argumentativas: la exposición cumple la función informativa, y la argumentación cumple la función persuasiva.

e) Empleo retórico de la hipertextualidad.

f) Utilización estratégica de las posibilidades retóricas de los diferentes modos de representación del conocimiento disponibles en el entorno digital. A partir de los criterios de evaluación establecidos por el docente para las producciones escritas, también se ensayará la autoevaluación y la corrección entre pares.

Es menester destacar que toda evaluación debe estar sometida a un proceso de reflexión, es decir, toda evaluación exige un proceso de metaevaluación (De Miguel Díaz, 2004, p. 12). Por un lado, los alumnos deben autoevaluar sus aprendizajes a fin de asumir una posición activa con respecto al proceso de construcción de sus 
conocimientos; por el otro lado, el docente debe evaluar las estrategias de enseñanza que utiliza, su modalidad, las instancias de evaluación administradas, etc.

Carlino (2010, pp. 113-114) sintetiza que una buena evaluación debe ser válida, explícita, educativa e internalizable: válida, porque sólo evalúa lo que se compromete a enseñar; explícita, porque el docente comparte con los estudiantes los criterios con los que serán evaluados; educativa, en tanto que promueve el aprendizaje; e internalizable, ya que tiene que ayudar a formar los criterios de la autoevaluación. Finalmente, Carlino subraya que la valoración de las producciones intermedias de los estudiantes debe ser informativa y no lapidaria, de tal manera que los oriente para reescribirlas. A su vez, sugiere que el docente y los alumnos reflexionen sobre la forma y el contenido del escrito, al inicio del proceso, como estándares de calidad; durante el proceso, como retroalimentación; y al final, como devolución global.

\section{Encuadre teórico}

Los distintos aspectos que hemos desarrollado a lo largo de este trabajo están enmarcados en diferentes planteamientos teóricos relacionados con la alfabetización académica, la alfabetización digital y la retórica visual digital.

Uno de los objetivos del presente proyecto es que las actividades y herramientas desarrolladas puedan ser de utilidad tanto para las materias que conforman el Núcleo de Formación Académica como para otras asignaturas. La formación de escritoras y escritores competentes en las prácticas discursivas y de pensamiento del nivel superior es un proceso que continúa permanentemente, ya que cada disciplina es un específico espacio conceptual-metodológico, pero también discursivo y retórico. Estos lineamientos se basan en los programas "escribir a través del currículum" (Writing across the curriculum) y "escribir en las disciplinas (Writing in the disciplines), presentes en varias universidades anglosajones7, que sostienen que la producción y el análisis de textos académicos debe ser un movimiento colectivo y permanente a lo largo de los ciclos universitarios. Carlino (2010) no sólo analiza los principales elementos teóricos de estos programas universitarios, sino que propone actividades de escritura, lectura y evaluación basadas en dichos programas, en teorías constructivistas del aprendizaje y en su propia experiencia docente. Green (2002), por su parte, explica que, en tanto existe una firme relación entre la escritura y el aprendizaje significativo, los docentes de todas las disciplinas deberían ocuparse de la enseñanza de las prácticas de la cultura escrita de sus especializaciones.

Así como compartimos la opinión de que la alfabetización académica es un proceso que debería desarrollarse a través del currículum, también consideramos que es necesario que la alfabetización digital esté presente en las diversas disciplinas de la educación superior. Para considerar este planteamiento, tomamos en primer lugar la perspectiva de Cassany (2000, p. 9), quien rechaza que las formas de lectura y escritura originadas por TIC sean una asignatura independiente del resto del currículum y sostiene que "la alfabetización tendría que dar prioridad o equivalencia a lo digital respecto a lo analógico". Para Nunberg (2005), de nada sirven los millones de dólares invertidos en conectar a las instituciones educativas a Internet si luego los estudiantes no saben encontrar información útil y pertinente en medio de la red; por lo tanto, el autor considera que la enseñanza de la lectura crítica en Internet, la hiperlectura, debe atravesar todos los niveles educativos y todos los cursos del currículum. 
En su última declaración sobre las culturas escritas del siglo XXI y las tecnologías digitales, la Asociación Internacional de Lectura (International Reading Association, 2009) sostiene que los responsables de los procesos de alfabetización deben integrar al currículum las nuevas formas de leer y de escribir, para que los alumnos puedan ejercer una exitosa participación cívica, económica y personal en la comunidad global. Los planes de estudio deberían darles a los alumnos oportunidades para leer, compartir y crear contenido junto con otros estudiantes alrededor del mundo. Es necesario que la alfabetización académica ofrezca a los alumnos una perspectiva crítica y cultural con respecto a las prácticas discursivas analógicas y digitales.

La creación de significado y la comprensión crítica de la información en entornos digitales se basa en una gramática híbrida, que es a la vez visual, verbal e interactiva; por lo tanto, los docentes, los responsables de los procesos de alfabetización académica necesariamente deberían ampliar su concepción de retórica, de producción textual y, en general, de alfabetización. Esta situación llevó a que diversos teóricos (Cope \& Kalantzis, 2000, 2009; The New London Group, 1996) acuñaran el término de "alfabetizaciones múltiples" o "multiliteracidades". Este concepto se refiere a dos aspectos centrales del uso del lenguaje hoy en día: por un lado, la variabilidad para construir significado en diferentes contextos sociales y culturales; por otro lado, a partir de las características de las nuevas tecnologías de la información y la comunicación, la construcción de significado se realiza, cada vez más, a través de formas multimodales (Cope \& Kalantzis, 2011).

El colectivo de teóricos llamado New London Group considera que, justamente, las tecnologías digitales fomentan una aproximación multimodal a la alfabetización, la cual utiliza las TIC para comprometer a los alumnos en una experiencia multisensorial y en una activa construcción del conocimiento. Según este grupo de teóricos, los estudiantes pueden trabajar desde sus culturas y múltiples identidades, usando sus propios lenguajes y sus experiencias cotidianas para diseñar nuevos tipos de conocimientos. Esta concepción de la alfabetización trata de formar a los estudiantes tanto como analistas críticos y como diseñadores de conocimiento (Hocks, 2003, p. 644).

Para Kress (1999), uno de los miembros del New London Group, crítica y diseño son dos procesos de construcción de conocimiento que se manifiestan en distintos contextos sociales y epistemológicos. En periodos de relativa estabilidad social, la crítica tiene la función de introducir dinamismo en el sistema, analizando las formas existentes y las relaciones sociales de las cuales son manifestaciones, para descubrir las reglas que las constituyen. En contraposición, el diseño es fundamental en momentos de gran cambio social, ya que da forma al futuro a través de la invención y la producción.

Hocks se basa en el planteamiento de Kress y explica que los docentes deben ofrecerles a los estudiantes la oportunidad de experimentar el proceso analítico de la crítica, que investiga las expectativas convencionales y las relaciones de poder, y el proceso transformador del diseño, que puede cambiar las relaciones de poder creando una nueva visión del conocimiento (644-645).

Por su parte, Cynthia L. Selfe y Gail E. Hawisher (2004) sostienen que las nuevas tecnologías y los nuevos medios demandan un abordaje multimodal de conceptos educativos claves como alfabetización y composición. Las TIC requieren también que se desarrollen nuevas pedagogías para enseñar composición multimodal que puedan efectivamente cruzar fronteras geopolíticas, lingüísticas y culturales. 
Las nuevas tecnologías de la información y la comunicación cambiaron la manera en que leemos, escribimos y pensamos. Los entornos digitales, con sus rasgos distintivos y características formales, permiten expandir nuestra concepción de la escritura. Para construir un texto, para crear significado, no sólo podemos apelar a las palabras y a las oraciones, sino que se pueden integrar imágenes, video, audio, animaciones, elementos interactivos, etc. Nuestro escrito tampoco tiene que basarse exclusivamente en un esquema de composición lineal, antes bien, la no linealidad se ha convertido en una opción más para el autor. A su vez, la conectividad y la interactividad conllevan a que la escritura no esté necesariamente diferida en tiempo y en espacio: la publicación, la recepción y la retroalimentación pueden realizarse prácticamente de forma simultánea. Finalmente, el autor puede argumentar utilizando la retórica clásica, pero también tiene la opción de hacer uso de las diferentes estrategias de la retórica visual, del esquema de composición espacial, de la hipertextualidad y de los diversos modos de representación del conocimiento; en definitiva, la argumentación en este tipo de entornos seguirá la dinámica de la retórica digital. Uno de los principales aspectos de estas nuevas prácticas letradas es que los límites entre autor y lector tienden a desaparecer. Si ya en uno de los primeros estudios sobre hipertextualidad Landow (1995) afirmaba que esta nueva tecnología diluía la unicidad textual, transformaba las nociones de propiedad intelectual y de autoría y configuraba un lector verdaderamente activo, la dinámica de la Web 2.0 directamente permite que los usuarios desarrollen por su cuenta contenidos digitales para publicarlos y diseminarlos, por lo tanto, todo lector es al mismo tiempo un escritor, editor y distribuidor. Incluso para aquellos usuarios que no producen contenidos, la lectura se complejiza, ya que es necesario comprender una gramática verbal, visual e interactiva, a través de la cual los textos digitales construyen significado.

Estas nuevas formas de leer y de escribir repercuten en todos los ámbitos sociales y culturales, incluida la esfera de la educación superior. Internet y los diversos dispositivos y medios digitales han transformado cómo investigamos, producimos, diseñamos, enseñamos y aprendemos. A continuación, desarrollaremos brevemente de qué manera podemos procesar estos cambios para ofrecerles a los alumnos una formación estratégica y actualizada.

Como docentes, especialistas e investigadores realizamos la mayor parte de nuestro trabajo intelectual a través de o con distintos medios digitales. Para realizar este proyecto, por ejemplo, consultamos bases de datos de revistas académicas electrónicas, leímos páginas Web y blogs especializados en alfabetización académica y digital, utilizamos el buscador de publicaciones académicas de Google, vimos y descargamos videos de YouTube sobre escritura digital, consultamos catálogos en línea de distintas bibliotecas, escribimos en el procesador de textos Word y diseñamos presentaciones multimodales en PowerPoint, establecimos contacto por correo electrónico o por Facebook con otros investigadores, etc. Si todas estas prácticas discursivas ya forman parte de la cultura escrita de la comunidad académica, ¿por qué no enseñar de forma sistemática y crítica estas competencias a aquellos estudiantes que recién ingresan a la esfera de la educación superior? Entonces, sería necesario ampliar nuestra concepción de cultura escrita y considerar que existen múltiples prácticas discursivas y de pensamiento que se desarrollan, se interconectan, se imbrican y se publican a través de y en los nuevos medios digitales. Creemos que el proceso de alfabetización académica debería tener en cuenta el concepto de multiliteracidades, a partir del cual la enseñanza de las prácticas de escritura y de lectura no se centraría sólo en las representaciones alfabéticas, sino que traería al aula las representaciones multimodales e interactivas de los medios digitales. 
En lo que respecta a las alumnas y los alumnos, una gran mayoría cuenta con un amplio caudal de conocimientos previos sobre los diversos géneros discursivos digitales, pero también suelen tener dificultades con la lectura crítica y la construcción de textos argumentativos, sobre todo en el desarrollo de una perspectiva retórica para la escritura. Coincidimos con DigiRhet.org (2006, p. 251) y con Cassany y Ayala (2008, p. 67) en que en el caso de las TIC es necesario aplicar efectivamente los planteamientos constructivistas y guiar, andamiar a los estudiantes para que puedan construir nuevos aprendizajes acerca de las prácticas letradas digitales y la alfabetización académica a partir de sus propios saberes previos sobre los medios digitales e interactivos. Debemos proporcionarles a los alumnos los contenidos teóricos, procedimentales y actitudinales que les permitan analizar y diseñar textos en entornos digitales, es decir, que puedan establecerse como críticos y productores de conocimiento. Publicaciones electrónicas como Computers and Composition Online, Kairos, Currents in Electronic Literacy, entre otras, ya se especializan en ensayos y artículos académicos digitales, en los cuales el video, el audio, las imágenes y el diseño forma parte de la dinámica argumentativa. Por ejemplo, el artículo “The Facebook Papers”, de Balzhier, Polk, Grover, Lauer, McNeely y Zmikly (2011), analiza cómo integrar Facebook a la enseñanza de escritura académica a los alumnos ingresantes. Lo destacable es que la propuesta teórica y pedagógica es llevada a la práctica, ya que el texto tiene el mismo diseño (con secciones de Muro, Notas, Amigos, etc.) y sigue la misma dinámica (la publicaciones más antiguas figuran al final de la página, etc.) que dicha red social.

Es menester aclarar que la retórica digital no se circunscribe sólo al ámbito académico, sino que también se desarrolla en la esfera periodística, gubernamental, comercial, polí- tica, publicitaria y cultural. Los docentes deben hacer explícito este nuevo horizonte a los alumnos, subrayando que su formación como escritores/lectores competentes en escritura digital, que pueden comprender críticamente y producir discursos retóricos digitales, es fundamental para participar y desempeñarse exitosamente en el ámbito académico, en el profesional y también en el ámbito cívico.

Anteriormente habíamos mencionado que la integración de las prácticas letras digitales a la alfabetización académica también respondía al perfil del graduado que aspirábamos formar. Consideramos que un futuro profesional en diseño y comunicación debe ser capaz, en primer lugar, de construir textos coherentes, cohesivos y adecuados, tanto analógicos como digitales. En la actualidad, en donde los medios digitales se multiplican y se actualizan, ofreciendo casi infinitas modalidades de representación, las y los profesionales deben poder discernir de manera estratégica qué modos son los más apropiados para lo que se desea comunicar, según la audiencia a la que se dirige y el propósito del mensaje a transmitir.

En tanto usuarios, ciudadanos, consumidores y miembros de la sociedad de la información, los estudiantes deberían comprender cómo la retórica digital influye en su cotidianidad. A continuación, expondremos algunos casos en donde la argumentación por y en medios digitales se encuentra presente.

Las campañas proselitistas a través de Facebook, YouTube y Flickr, la llamada "militancia 2.0", el uso del Twitter para comunicar la actividad diaria de figuras políticas y funcionarios públicos, etc., son sólo algunos ejemplos de cómo el discurso argumentativo digital se emplea en la arena política. Sobre esta temática, se destaca el trabaja de Losh (2009), quien analiza cómo el Gobierno de Estados Unidos emplea estrategias de retórica digital para difundir sus lineamientos ideológicos a través de sitios Web gubernamentales, video juegos, tours virtuales de monumentos nacionales, salas de chat, tutoriales on line, etc. 
Por otro lado, la utilización de las TIC para la difusión de acontecimientos sociales y políticos, la organización de protestas o el debate ideológico en torno a hechos que suscitan controversia, acciones que se dieron el caso de, por ejemplo, la operación militar israelí Plomo Fundido contra el Líbano, el ataque al buque turco Mavi Marmara al intentar romper el bloqueo de la Franja de Gaza, los recientes levantamientos populares en los países árabes y las protestas estudiantiles en Chile, y cómo los diversos medios periodísticos (masivos, oficiales y alternativos) cubrieron estos sucesos desde sus plataformas digitales, evidencian distintas estrategias de la retórica digital para persuadir, informar o motivar a la acción. Finalmente, las campañas de marketing viral, los enlaces patrocinados, las publicaciones pagas sobre productos y servicios en blogs y sitios Web de especialistas y de formadores de opinión, etc., también hacen uso de la argumentación a través de la multimodalidad, la composición espacial, la interactividad y la hipertextualidad que ofrecen los entornos digitales. Estos ejemplos permiten observar que producir y analizar textos argumentativos del género discursivo digital no es una competencia que se circunscribe solamente al ámbito académico. Las estrategias y las técnicas para leer críticamente o componer un documento digital a partir de una perspectiva retórica, desarrolladas por los alumnos en el proceso de alfabetización académica, serán centrales para su formación como ciudadanos y consumidores concientizados. Los estudiantes establecerán una distancia analítica hacia los contenidos digitales comerciales o políticos, ya que, por un lado, poseerán los protocolos para una lectura crítica, y por el otro, conocerán de primera mano la dinámica retórica de los documentos digitales al haber sido ellos mismos productores y diseñadores.

En el presente Proyecto de Exploración de la Agenda Profesional realizamos una primera aproximación a las características distintivas de los géneros discursivos digitales y luego propusimos su integración al proceso de alfabetización académica, porque consideramos que la enseñanza sistemática de las prácticas discursivas y de pensamiento que se originan a partir de las TIC permite que el alumno adquiera competencias fundamentales para su carrera académica y su futuro profesional. Deseamos que los aspectos teóricos y las propuestas de actividades que se presentaron en el proyecto sean de utilidad tanto para los docentes y los especialistas responsables de espacios curriculares relacionados con la alfabetización académica como para los profesores de otras materias, ya que creemos que la producción y el análisis de textos académicos, en cualquier soporte, debe ser un proceso permanente y colectivo a lo largo de los distintos niveles universitarios.

Notas

1. Para más información acerca de las consideraciones pedagógicas del modelo 1 a 1 véase Piscitelli (2007), Tedesco (2009), Sagol (2010), Pulfer, Toscano, Rexach y Asenjo (2011).

2 Tomamos la clasificación establecida por Rowlands y Williams (2007, pp. 27-28), quienes designan

"Generación Google" a aquellos que nacieron a partir de 1994; "Generación Y", a los nacidos entre 1978 y 1993; y "Generación C, a las personas nacidas antes de 1978.

3. Con respecto a la palabra literacy, Nunberg (2005) explica que "ningún otro idioma tiene una palabra que abarque un territorio tan amplio, desde habilidades de lectura y escritura, pasando por la familiarización con la cultura escrita, hasta competencias básica en materias como Matemática o Geografía" [traducción nuestra].

4. Recordemos que, según la teoría de Bajtin (1997), los géneros, en tanto tipos relativamente estables y normativos de enunciados, comparten características temáticas, de estructura y de estilo. 
5. Según Aarseth (1997, p. 72), un texto no lineal "es un objeto de comunicación verbal que no consiste simplemente en una secuencia fija de letras, palabras y frases; es un texto cuyas palabras o secuencias de palabras pueden variar de lectura en lectura debido a la forma, las convenciones o los mecanismo del texto". A partir de esta definición, el autor propone cuatro categorías pragmáticas o grados de linealidad: "1) el texto no lineal, cuyos téxtones [o lexías] resultan totalmente estáticos, abiertos y explorables para el usuario; 2) el texto no lineal discontinuo o hipertexto, que puede cruzarse con "saltos" (enlaces explícitos) de un texton a otro; 3) el "cibertexto" determinado, en el que el comportamiento de los téxtones es predecible aunque condicional y con el elemento de la representación de rol, y 4) el cibertexto indeterminado, cuyos téxtones son dinámicos e impredecibles" (Aarseth, 1997, p. 84).

6. El Diccionario de la lengua española de la Real Academia Española define traslaticio como "el sentido en que se usa un vocablo para que signifique o denote algo distinto de lo que con él se expresa cuando se emplea en su acepción primitiva o más propia y corriente".

7. Entre las instituciones que poseen los programas Writing across the curriculum (Escribir a través del currículum) y Writing in the disciplines (Escribir en las disciplinas) podemos mencionar la Universidad de Cornell, la Universidad Estatal de Washington, el Instituto Tecnológico de Massachusetts, la Universidad Estatal de Georgia, la Universidad de Filadelfia, la Universidad de Texas Austin, la Universidad George Washington, la Universidad de Nuevo México, la Universidad Edith Cowan, etc.

Bibliografía

Aarseth, E. J. (1997). No linealidad y teoría literaria. En George P. Landow (Comp.). Teoría del hipertexto. Barcelona: Paidós, pp. 71-108.

Adelstein, A, López Casanova, M., Inza, M., Korfield, L., Kruguel, I., Muslip, E., Pereira, C., Peralta, D. y Resnik, G. (1998-1999). Taller de Lecto-Escritura. Vol. 1 y 2. Buenos Aires: Servicio de Publicaciones de la Universidad Nacional de General Sarmiento.

Alvarado, M. (1994). Paratexto. Buenos Aires: Instituto de Lingüística-Facultad de Filosofía y Letras, Cátedra de Semiología y Oficina de Publicaciones-Ciclo Básico Común UBA.

Alvarado, M. y Yeannoteguy, A. (2009). La escritura y sus formas discursivas. $4^{\circ}$ reimpresión. Buenos Aires: Eudeba.

Arnoux, E., Di Stefano, M., Pereira, M. C. (2000). Prácticas de lectura y escritura en la universidad. Buenos Aires: Ciclo Básico Común UBA.

Bajtin, M. (1997). El problema de los géneros discursivos. En Estética de la creación verbal. Buenos Aires: Siglo $\mathrm{XXI}$.

Balzhiser, D., Polk, J. D., Grover, M., Lauer, E., McNeely, S., Zmikly, J. (2011). The Facebook Papers. Kairos: A Journal of Rhetoric, Technology, and Pedagogy, 16, 1. Disponible en: http://kairos.technorhetoric.net/16.1/praxis/balzhiser-et-al/info.htm. 
Bardi, V., Perazzo, M., Ruíz, M., Sosisky, G. (2007). Cómo evaluar sitios y recursos educativos de Internet. Educ.ar, 25 de julio. Disponible en: http://www.educ.ar/educar/site/secure/educar/area-usuario/como-evaluarsitios-y-recursos-educativos-de-internet.html Bianchini, A. (1999). Conceptos y definiciones del hipertexto. Reporte interno Cl 1999. Caracas: Departamento de Computación y Tecnología de la Información-Universidad Simón Bolívar.

Botta, M. y Warley, J. (2007). Tesis, tesinas, monografías e informes. Nuevas normas y técnicas de investigación y redacción. Buenos Aires: Biblos.

Bourdieu, P. y Gros, F. (1990). Principios para una reflexión sobre los contenidos de la enseñanza. Revista de Educación, $n^{\circ} 292$.

Burbules, N. (1997). Rhetorics of the Web: hyperreading and critical literacy. En Ilana Snyder (Ed.). Page to Screen. Taking Literacy into the Electronic Era. Londres: Routledge, pp. 102-122.

Burbules, N. y Callister, T. A. (2001). Educación: riesgos y promesas de las nuevas tecnologías de la información. Barcelona: Granica. Carlino, P. (2003). Alfabetización académica: un cambio necesario, algunas tentativas posibles. Educere, año 6, 20 (enero-febrero-marzo), pp. 409-420.

(2006). La escritura en la investigación. Documento de trabajo $n^{\circ} 19$. Victoria: Escuela de Educación-Universidad de San Andrés.

(Coord.) (2004). Textos en contexto. Leer y escribir en la universidad. Buenos Aires: Ediciones Lectura y Vida.

(2010). Escribir, leer y aprender en la universidad. Una introducción a la alfabetización académica. $5^{\circ}$ reimpresión. Buenos Aires: Fondo de Cultura Económica.

Cassany, D. (2000). De lo analógico a lo digital. El futuro de la enseñanza de la composición. Lectura y Vida, 21/4, pp. 6-15.

(2001). Decálogo didáctico de la enseñanza de la composición. Glosas Didácticas: Revista electrónica internacional de didáctica de las lenguas y sus culturas, 4. Disponible en: (2002). La alfabetización digital. Actas del XII Congreso Internacional de la Asociación de Lingüística y Filología de América Latina (ALFAL).

(2005). Navegar con timón crítico. Cuadernos de pedagogía, 352, pp. 36-39. Disponible

en: (2006). Tras las líneas. Sobre la lectura contemporánea. Barcelona: Anagrama.

(2008). Describir el escribir: cómo se aprende a escribir. $6^{\circ}$ reimpresión. Buenos Aires: Paidós. (2009). La cocina de la escritura. $16^{\circ}$ edición. Barcelona: Anagrama.

Cassany, D. y Ayala, G. (2008). Nativos e inmigrantes digitales en la escuela. CCE Participación Educativa, 9 , pp. 53-71. 
Chartier, R. (2008). Aprender a leer, leer para aprender. En José Antonio Millán (Coord.). La lectura en España. Informe 2008: Leer para aprender. Madrid: Fundación Germán Sánchez Ruipérez y Federación de Gremios Editores de España, pp. 23-42.

Ciapuscio, G. (2000). La monografía en la universidad: ¿una clase textual? Humanitas. Revista de la Facultad de Filosofía y Letras, Universidad Nacional de Tucumán, año XXIII, nº 30-31, pp. 237-253.

Cope, B. \& Kalantzis, M. (Eds.). (2000). Multiliteracies: Literacy learning and the design of social futures. London: Routledge.

(2009). "Multiliteracies": New Literacies, New Learning. Pedagogies: An International Journal, 4, 3, pp. 164-195.

(2011). Expanding the Scope of Literacy Pedagogy. New Learning. Transformational Designs for Pedagogy and Assessment. Disponible en: De Miguel Díaz, M. (2004). Nuevos retos en el ámbito de la evaluación. Actas del XI Congreso sobre Modelos de Investigación. Madrid: La muralla.

De Volder, C., Russo, F. y Kolesas, M. (2010). La información en Internet. $1^{\text {a }}$ parte: dónde y cómo buscar información. Buenos Aires: Biblioteca del Docente.

Di Marzo, L. (2006). Leer en entornos digitales: la comunicación, la inmediatez, la tecnología, el entusiasmo y la finitud. 12 (ntes), 9 (noviembre), pp. 8-9. Di Stefano, M. y Pereira, M. C. (2004). La enseñanza de la lectura y la escritura en el nivel superior: Procesos, prácticas y representaciones sociales. En Paula Carlino (Coord.).

Textos en contexto. Leer y escribir en la universidad. Buenos Aires: Ediciones Lectura y Vida.

DeVoss, D. N., Cushman, E., Grabill, J. T. (2005). Infrastructure and Composing: The When of New-Media Writing. College Composition and Communication, Vol. 57, No. 1 (septiembre), pp. 14-44.

DeVoss, D. N., \& Porter, J. E. (2006). Why Napster Matters to Writing: Filesharing as a New Ethic of Digital Delivery. Computers and Composition, 23, pp. 178-210.

DigiRhet.org. (2006). Teaching digital rhetoric: Community, critical engagement, and application. Pedagogy: Critical Approaches to Teaching Literature, Language, Composition, and Culture, vol. 6, n 2, pp. 231-259.

Fainholc, B. (2004) Lectura crítica en Internet. Análisis y utilización de los recursos tecnológicos en educación. Rosario: Homo Sapiens Ediciones.

Fallows, D. (2005). Search Engine Users. Internet searchers are confident, satisfied and trusting - but they are also unaware and naïve. Washington D.C.: Pew Internet \& American Life Project. Disponible en: Green, B. (2002). A Literacy Project of Our Own? English in Australia, vol. 44, n 134 (julio) Disponible en: Handa, C. (2001). Letter from the Guest Editor: Digital Rhetoric, Literacy, Computers, and Composition. Computers and Composition, 18, pp. 1-10. 
Heba, G. (1997). HyperRhetoric: Multimedia, Literacy, and the Future of Composition. Computers and Composition, 14 (enero), pp. 19-44.

Hocks, M. E. (2003). Understanding Visual Rhetoric in Digital Writing Environments. College Composition and Communication, vol. 54, 4 (junio), pp. 629-656.

International Reading Association. (2009). New Literacies and the 21st-Century Technologies. A Position Statement of the International Reading Association. Newark: International Reading Association.

Kolb, D. (1997). Sócrates en el laberinto. En George P. Landow (Comp.). Teoría del hipertexto. Barcelona: Paidós, pp. 365-388.

Kress, G. (1998). Visual and verbal modes of representation in electronically mediated communication: the potencials of new form of text. En Ilana Syder (Ed.). Page to screen: taking literacy into the electronic era. Londres: Routledge, pp. 53-79.

(1999). English at the Crossroads: Rethinking Curricula of Communication in the Context of the Turn to the Visual. En Gail E. Hawisher y Cynthia L. Selfe. (Ed.). Passions, Pedagogies and 21st Century Technologies. Logan: Utah State University Press, pp. 66-88.

(2004). Reading Images: Multimodality, Representation and New Media. IIID. Expert Forum for Knowledge Presentation Resources for Communication. Mayo 30-31, 2003, Institute of Design, IIT Chicago, IL. Disponible en: (2005). Pictures from a rocket: English and the semiotic take. English Teaching: Practice and Critique, volumen 4, número 1 (mayo), pp. 95-105. Disponible en: Kress, G. \& van Leeuwen, T. (2006). Reading Images: the grammar of visual design. $2^{\circ}$ edición. Londres-Nueva York: Routledge.

Landow, G. P. (1995). Hipertexto. La convergencia de la teoría crítica contemporánea y la tecnología. Barcelona: Paidós.

Landow, G. P. (Comp.) (1997). Teoría del hipertexto. Barcelona: Paidós.

Lanham, R. A. (1992). Digital rhetoric: Theory, practice, and property. En M. C. Tuman (Ed.). Literacy online: The promise (and peril) of reading and writing with computers. Pittsburgh: University of Pittsburgh Press, pp. 221243.

(1993). The Electronic Word: Democracy, Technology, and the Arts. Chicago: University of Chicago

Press.

Litwin, E. (1998). La evaluación: campo de controversias y paradojas o un nuevo lugar para la buena enseñanza. En Alicia R. W. de Camilloni y otros. La evaluación de los aprendizajes en el debate didáctico contemporáneo. Buenos Aires: Paidós, pp. 11-33.

Losh, E. (2008). Government YouTube. Bureaucracy, Surveillance, and Legalism in StateSanctioned Online Video Channels. En Geert Lovink \& Sabine Niederer (Eds.). Video Vortex Reader: Responses to YouTube. Rotterdam: Institute of Network Cultures, pp. 111-124. 
Disaster, Miscommunication, and Mistakes. Cambridge: The MIT Press.

Manovich, L. (2006). El lenguaje de los nuevos medios de comunicación. La imagen en la era digital. Buenos Aires: Paidós.

Martí Cartes, F. (2006). Llegir, pensar i clicar. Proposta per llegir críticament a Internet. Barcelona: Generalitat de Catalunya.

(2008). Llegir la credibilitat dels webs: estudi de cas. Articles de didàctica de la llengua i la literatura,

44: 59-74.

Martínez Rodrigo, E., y González Fernández, A. M. (2010). La comunicación digital: nuevas formas de lecturaescritura. Quaderns Digitals, 63. Disponible en: Millán, J. A. (2008) Los modos de la lectura digital. En José Antonio Millán (Coord.). La lectura en España. Informe 2008: Leer para aprender. Madrid: Fundación Germán Sánchez Ruipérez y Federación de Gremios Editores de España, pp. 299-314.

National Writing Project, DeVoss, D. N., Eidman-Aadahl, E., Hicks, T. (2010). Because Digital Writing Matters. Improving student writing in online and multimedia environments. San Francisco: Jossey-Bass.

Nelson, T. H. (1981). Literary machines. Sausalito: Mindful Press.

Nunberg, G. (2005). Teaching Students to Swim in the Online Sea. The New York Times, 13 de febrero. Disponible en: O'Reilly, T. (2005). What Is Web 2.0. Design Patterns and Business Models for the Next Generation of Software. O'Reilly, 30 de septiembre.Disponible en: Piscitelli, A. (2007). Historia y presente de los modelos 1 a 1. Educ.ar, 12 de marzo.Disponible en: (2009). Recovering Delivery for Digital Rhetoric and Human-Computer Interaction. Computers and Composition, vol. 26, 4, pp. 207-224.

Pozo, J. I. (2001). ¿Por qué no aprenden los alumnos universitarios lo que se les quiere enseñar? Docencia universitaria, vol. 2, $\mathrm{n}^{\circ} 2$ (agosto).Disponible en: Prado Aragonés, J. (2001). Hacia un nuevo concepto de alfabetización. El lenguaje de los medios. Comunicar 16, pp. 161-170.

Prensky, M. (2001a). Digital Natives, Digital Inmigrants. On the Horizon, vol. 9, 5 (octubre).

(2001b). Digital Natives, Digital Immigrants, Part II: Do They Really Think Differently? On the Horizon, vol. 9, 6 (diciembre).

Pulfer, D., Toscano, J. C., Rexach, V., Asenjo, J. (Coords.) (2011). Revista Iberoamericana de Educación. Número monográfico: modelo 1 a 1, 56 (mayo-agosto).

Reeves, L. M. et al. (2004). Guidelines for multimodal user interface design.Communications of the ACM, vol. 47, 1 (enero), pp. 57-59.

Sagol, C. (2010). Netbooks en el aula. Introducción al modelo 1:1 e ideas para trabajar en clase. Buenos Aires: Ministerio de Educación de la Nación. 
Scagnoli, N. I. (2001). Evaluación de recursos en Internet. Teoría y materiales complementarios del taller a distancia. Champaign: University of Illinois at Urbana Champaign.

Selfe, C. L., \& Hawisher, G. E. (Eds.) (2004). Literate Lives in the Information Age: Narratives of Literacy from the United States. Mahwah: Lawrence Erlbaum.

Stroupe, Craig. (2000). Visualizing English: Recognizing the Hybrid Literacy of Visual and Verbal Authorship on the Web. College English, 62, 5 (mayo), pp. 607-632.

Sullivan, P. (2001). Practicing safe visual rhetoric on the World Wide Web. Computers and Composition, 18, 2, pp. 103-121.

Tedesco, J. C. (2009). La opción de una PC por alumno. La Nación, 27 de octubre. Disponible en: The New London Group. (1996). A pedagogy of multiliteracies: Designing social futures. Harvard Educational Review, vol. $66, N^{\circ} 1$ (primavera), pp. 60-92.

Vásquez Rocca, A. (2004). El hipertexto y las nuevas retóricas de la postmodernidad. Textualidad, redes y discurso ex-céntrico. Philosophica. Revista del Instituto de Filosofía de la Pontificia Universidad Católica de Valparaíso, $\mathrm{N}^{\circ} 27$.

Welch, K. (1990). Electrifying Classical Rhetoric: Ancient Media, Modern Technology, and Contemporary Composition. JAC, 10, 1.

Williams, P. y Rowlands, I. (2007). Information Behaviour of the Researcher of The Future. A British Library and JISC Study (Joint Information Systems Committee). The Literature on Young People and their Information Behaviour (Work Package II).

Writing in Digital Environments Research Center (WIDE) (2005). Why Teach Digital Writing? Kairos: A Journal of Rhetoric, Technology, and Pedagogy, 10.1. Disponible en: Wysocki, A. F. (1998). Monitoring Order. Kairos: A Journal of Rhetoric, Technology, and Pedagogy, 3.2. Disponible en: < http://www.technorhetoric.net/3.2/binder.html?features/wysocki/mOrder0.html> (2001). Impossibly Distinct: On Form/Content and Word/ Image in Two Pieces of Computer-Based Interactive Multimedia. Computers and Composition, 18, pp. 137-162.

(2004). The Multiple Media of Texts: How Onscreen and Paper Texts Incorporate Words, Images, and Other Media. En Charles Bazerman \& Paul Prior (Eds.). What Writing Does and How It Does It: An Introduction to Analyzing Texts and Textual Practices. Mahwah: Lawrence Erlbaum Associates.

Zappen, J. P. (2005). Digital Rhetoric: Toward an Integrated Theory. Technical Communication Quarterly, 14, 3, pp. 319-325.

2.2. Alfabetización académica en entornos digitales fue publicado de la página 203 a página242 en Cuadernos del Centro de Estudios de Diseño y Comunicación № 63 